\title{
A High Power Beam-on-target Test of Liquid Lithium Target for RIA
}

prepared by

Physics Division and Nuclear Engineering Division

Argonne National Laboratory 


\begin{abstract}
About Argonne National Laboratory
Argonne is managed by The University of Chicago for the U.S. Department of Energy under contract W-31-109-Eng-38. The Laboratory's main facility is outside Chicago, at 9700 South Cass Avenue, Argonne, Illinois 60439. For information about Argonne and its pioneering science and technology programs, see www.anl.gov.
\end{abstract}

\title{
Availability of This Report
}

This report is available, at no cost, at http://www.osti.gov/bridge. It is also available on paper to U.S. Department of Energy and its contractors, for a processing fee, from:

U.S. Department of Energy

Office of Scientific and Technical Information

P.O. Box 62

Oak Ridge, TN 37831-0062

phone (865) 576-8401

fax (865) 576-5728

reports@adonis.osti.gov

\section{Disclaimer}

This report was prepared as an account of work sponsored by an agency of the United States Government. Neither the United States Government nor any agency thereof, nor The University of Chicago, nor any of their employees or officers, makes any warranty, express or implied, or assumes any legal liability or responsibility for the accuracy, completeness, or usefulness of any information, apparatus, product, or process disclosed, or represents that its use would not infringe privately owned rights. Reference herein to any specific commercial product, process, or service by trade name, trademark, manufacturer, or otherwise, does not necessarily constitute or imply its endorsement, recommendation, or favoring by the United States Government or any agency thereof. The views and opinions of document authors expressed herein do not necessarily state or reflect those of the United States Government or any agency thereof, Argonne National Laboratory, or The University of Chicago. 


\section{A High Power Beam-on-target Test of Liquid Lithium Target for RIA}

by

Jerry Nolen, Claude Reed, Vincent Novick, James Specht, Perry Plotkin,

Yoichi Momozaki, and Itacil Gomes (I.C.Gomes Consulting \& Investment Inc.)

Physics Division and Nuclear Engineering Division, Argonne National Laboratory

August 22, 2005
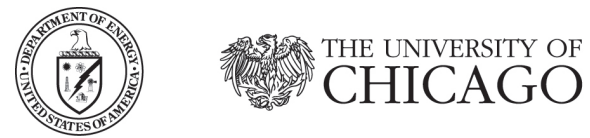

$02 \begin{aligned} & \text { Office of } \\ & \text { Science }\end{aligned}$

Argonne National Laboratory is managed by

The University of Chicago for the U.S. Department of Energy 


\section{Table of Content}

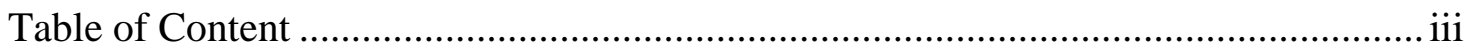

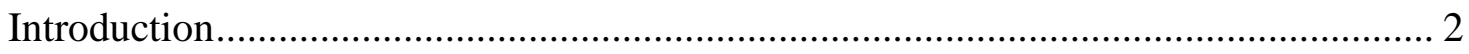

Engineering and Safety Issues of Lithium Targets .......................................................... 3

Conceptual Description of the Windowless Liquid Lithium Target............................. 3

The Choice of Liquid Lithium ..................................................................................... 5

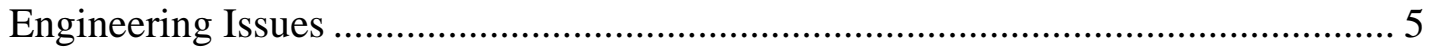

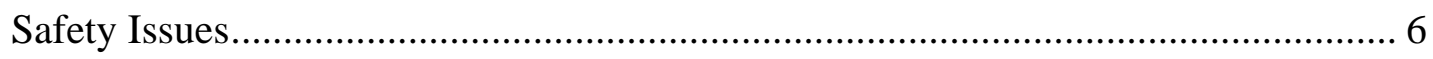

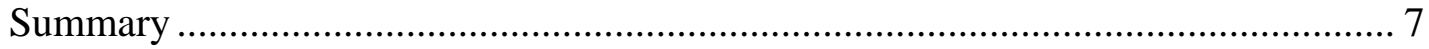

Heat Deposition in a Lithium Jet by an E-Beam ........................................................ 7

Description of the Model Used ............................................................................ 7

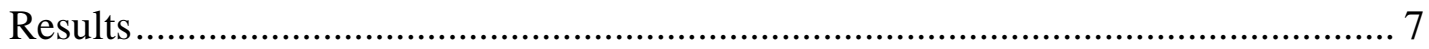

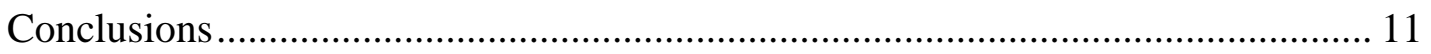

A 20 kW Beam-on-Target Test of a High-Power Liquid Lithium Target for RIA ...... 11

Description of Beam-on-Target Setup ................................................................... 11

Instrumentation and Data Acquisition .................................................................. 12

Experimental Procedure .................................................................................... 17

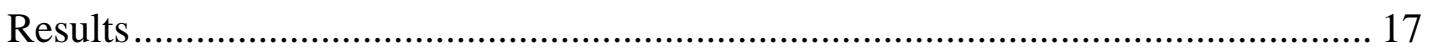

Summary and Conclusions ................................................................................. 21

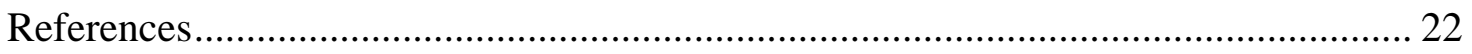




\begin{abstract}
Experiments were conducted to demonstrate the stable operation of a windowless liquid lithium target under extreme thermal loads that are equivalent to uranium beams from the proposed Rare Isotope Accelerator (RIA) driver linac. The engineering and safety issues accompanying liquid lithium systems are first discussed. The liquid metal technology knowledge base generated primarily for fast reactors, and liquid metal cooled fusion reactors, was applied to the development of these systems in a nuclear physics laboratory setting. The use of a high energy electron beam for simulating a high power uranium beam produced by the RIA driver linac is also described. Calculations were performed to obtain energy deposition profiles produced by electron beams at up to a few $\mathrm{MeV}$ to compare with expected uranium beam energy deposition profiles. It was concluded that an experimental simulation using a 1-MeV electron beam would be a valuable tool to assess beam-jet interaction. In the experiments, the cross section of the windowless liquid lithium target was $5 \mathrm{~mm} \times 10 \mathrm{~mm}$, which is a $1 / 3$ rd scale prototype target, and the velocity of the liquid lithium was varied up to $6 \mathrm{~m} / \mathrm{s}$. Thermal loads up to $20 \mathrm{~kW}$ within a beam spot diameter of $1 \mathrm{~mm}$ were applied on the windowless liquid lithium target by the $1-\mathrm{MeV}$ electron beam. The calculations showed that the maximum power density and total power deposited within the target, from the electron beam, was equivalent to that of a $200-\mathrm{kW}, 400-\mathrm{MeV} / \mathrm{u}$ uranium beam. It was demonstrated that the windowless liquid lithium target flowing at velocities as low as $1.8 \mathrm{~m} / \mathrm{s}$ stably operated under beam powers up to $20 \mathrm{~kW}$ without disruption or excessive vaporization.
\end{abstract}




\section{Introduction}

The Rare Isotope Accelerator (RIA) is a new project to produce various unstable isotope beams. A high power ion beam is generated in a driver linac and delivered to targets for isotope production [1], [2]. For a low $Z$ target concept (for example, lithium) using heavy-ion fragmentation reactions, ion optical systems for separating unstable fragments following the target require the beam spot size on the target to be $1 \mathrm{~mm}$ in diameter [3], [4]. The peak energy deposition in the target reaches $2 \mathrm{MW} / \mathrm{cm}^{3}$ when a uranium beam of $200 \mathrm{~kW}$ is applied. One of the challenges in RIA is to develop a target that withstands such extreme thermal loads from powerful ion beam bombardment. No solid target is expected to survive under such intense thermal loads, making a liquid target, especially a liquid lithium target, a good alternative due to its preferable nuclear and thermal properties [1], [3]. Because of the low vapor pressure of lithium, the liquid lithium target could be configured as a so-called windowless target (all liquid, no solid confinement structures around). Specifically, a windowless target for the production of radioactive ions via fragmentation, consisting of a jet of about $3 \mathrm{~cm}$ thickness of flowing liquid lithium, exposed to the beamline vacuum [1], [4] is being developed. Since no windowless target systems, with power densities equivalent to a RIA uranium beam, have been tested in actual accelerator applications, the feasibility of the windowless target must be demonstrated while operating under similar conditions to those in RIA.

Although lithium has excellent and well known thermal properties, it is not well known how liquid lithium interacts with high energy beams from thermal and hydrodynamic view points. For example, high energy deposition in a small area on the liquid lithium could facilitate local vaporization or even boiling of lithium. If this local vaporization of lithium is significant, it may prohibitively increase the pressure in the beamline. It would also be possible that such a local vaporization might cause hydrodynamic disturbances in the liquid target. When the amplitude of these induced disturbances is comparable to the scale of the liquid target (order of a centimeter), the liquid target could disrupt. To answer these questions, it is necessary to conduct an experiment in which a liquid lithium jet, with similar physical dimensions to those of an actual target in RIA, is irradiated by a beam applying similar thermal loads to the jet.

The main objective of the present work is to demonstrate the stable formation of a liquid lithium jet simulating the windowless liquid lithium target in RIA while being heated by a beam simulating a high power ion beam. The first section of this report discusses the engineering and safety issues accompanying liquid lithium systems for the windowless target. The liquid metal technology knowledge base, generated primarily for fast reactors, and liquid metal cooled fusion reactors, was applied to the development of these systems in a nuclear physics laboratory setting. In the next section, the use of an electron beam, to simulate a high-power, uranium beam produced by the RIA driver linac is justified. Calculations using MCNPX were performed to obtain the energy deposition

profile produced by a few-MeV electron beam to compare with the expected uranium beam energy deposition. These calculations have shown that high energy electron beams can simulate uranium beam energy deposition in flowing lithium, supporting a use of 
electron beams as a heat source in this work. The maximum power density deposited within the jet by a $20-\mathrm{kW}, 1-\mathrm{MeV}$ electron beam was equivalent to that of a $200-\mathrm{kW}$, $400-\mathrm{MeV} / \mathrm{u}$ uranium beam. The subsequent section describes details of the high-power, beam-on-target test and results. The experimental setup used in this work included a lithium loop, beamline, electron beam source, and various instrumentations. A Dynamitron was used as an electron beam source, which was connected to the lithium loop with a beamline. The behavior of the liquid lithium jet was visually observed to confirm a stable jet during heating. The temperatures at various locations and the background pressure were also monitored to evaluate the capability of the jet to handle an extreme thermal load without excessive vaporization. One mechanically movable, traversing thermocouple (TC) was mounted near the jet to measure the temperature distribution across the jet. Also used was an infrared (IR) camera to monitor the surface temperature profile of the jet. At a jet velocity of $10 \mathrm{~m} / \mathrm{s}$, a 20-kW, 1-mm diameter beam was expected to produce about $90{ }^{\circ} \mathrm{C}$ surface temperature rise across the beam spot; at half that velocity, the surface temperature rise will double. The effects of the beam-jet interaction on the production of lithium vapor and its effect upon beamline vacuum were also evaluated.

\section{Engineering and Safety Issues of Lithium Targets}

\section{Conceptual Description of the Windowless Liquid Lithium Target}

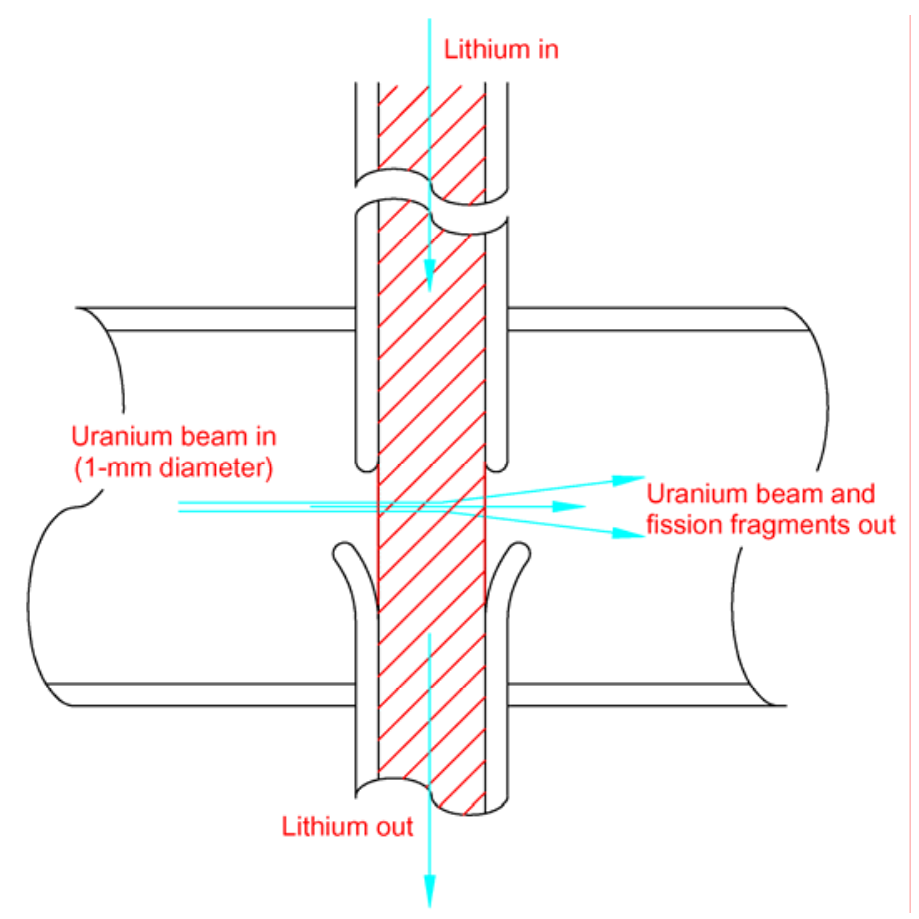

Figure 1. Schematic layout of the concept of a windowless liquid lithium target for in-flight fission or fragmentation of heavy ions up to uranium, designed to work with beam powers as high as $400 \mathrm{~kW}$. 

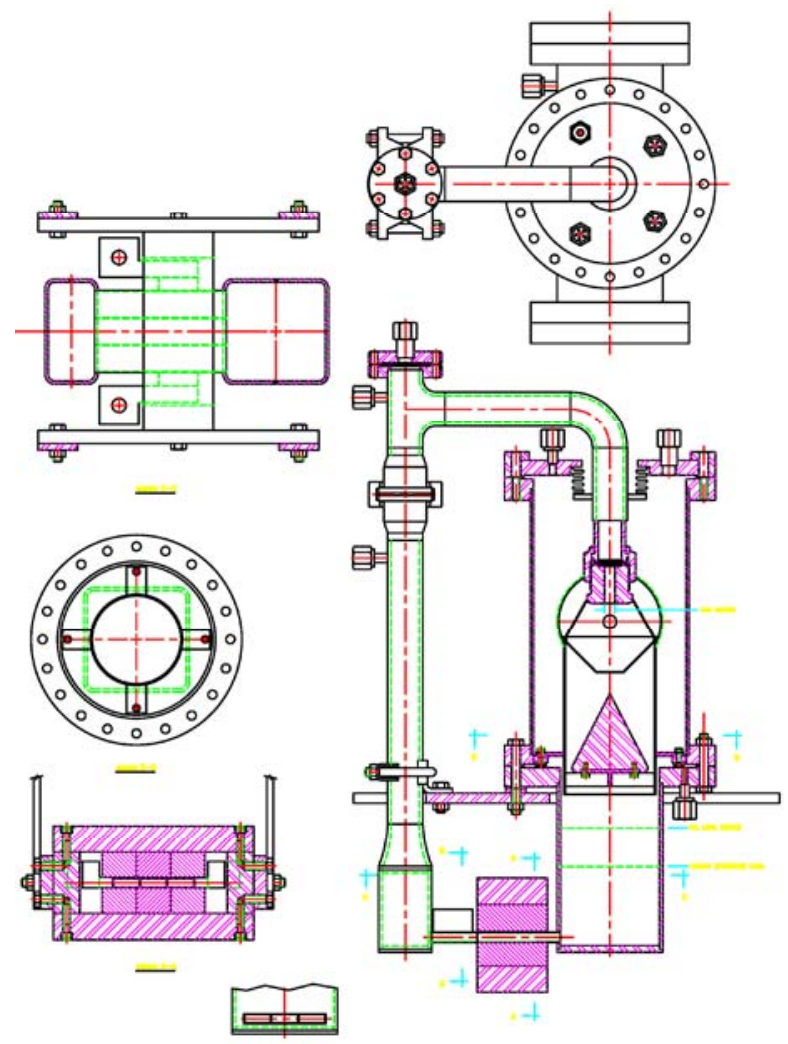

Figure 2. Mechanical drawing of the liquid lithium target loop. The overall height of the loop is $0.6 \mathrm{~m}$. A section view of the permanent magnet pump is shown at the lower left.

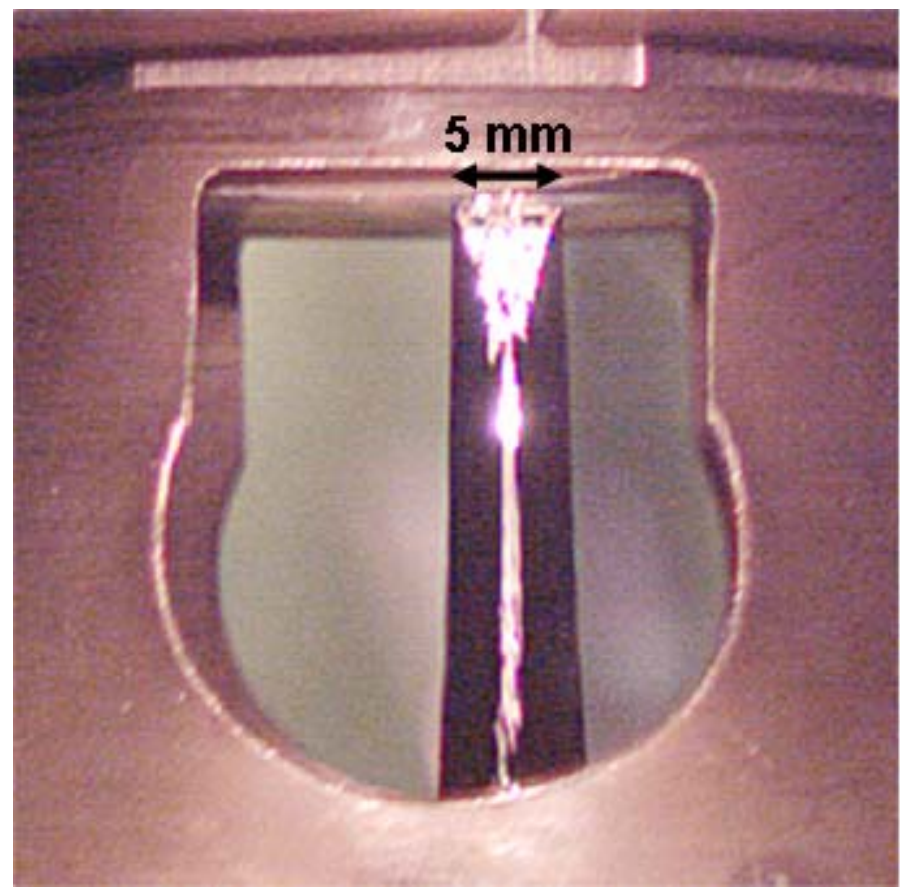

Figure $3.5 \mathrm{~mm} \times 10 \mathrm{~mm}$ liquid lithium jet in vacuuo. 
One particular application of liquid lithium technology in RIA, shown schematically in Figure 1, is a windowless target for the production of radioactive ions via fragmentation, consisting of a jet of about $3 \mathrm{~cm}$ thickness of flowing liquid lithium, exposed to the beamline vacuum [1], [4]. A 1/3rd scale prototype of a liquid lithium windowless target loop was build and is shown in Figure 2. A $5 \mathrm{~mm} \times 10 \mathrm{~mm}$ flowing lithium jet, i.e. windowless target, in vacuum produced in the loop is also shown in Figure 3.

\section{The Choice of Liquid Lithium}

For the heavy-ion fragmentation targets, the low $\mathrm{Z}$ of Li provides an ideal target while additionally functioning to carry away the heat generated; for light-ion beams on high $Z$ targets (e.g. W), Li serves as an ideal low $Z$ coolant. In both cases, a liquid metal is necessary from high power heat removal considerations. Liquid metals have significantly higher thermal conductivity and lower specific heat than ordinary liquids and gases. In convective heat transfer, these thermophysical properties combine to produce the low Prandtl number $(\mathrm{Pr})$ characteristic of liquid metals, compared to ordinary fluids. Typically, for liquid metals $0.003 \leq \operatorname{Pr} \leq 0.06$, while for other liquids and gases $\operatorname{Pr} \geq 0.2$. Under turbulent flow conditions, eddy conduction of heat becomes important and the process of heat transfer is determined by both molecular and eddy conduction in the various flow regions of a fluid stream. Whereas in ordinary fluids molecular conduction is only significant near the wall (in the laminar sub layer), in a liquid metal the magnitude of the molecular conductivity is of the same order as the eddy conductivity, and accordingly, the effects of molecular conduction are felt not only in the boundary layers, but also extend well into the turbulent core of the fluid. In this context, the Prandtl number can be thought of as expressing the ratio of the viscous boundarylayer thickness to the thermal boundary-layer thickness. Therefore the fundamental details of the heat transfer mechanisms in liquid metals differ significantly from those observed in ordinary fluids, and this difference is the reason for their excellence in convective heat transfer [5]. Lithium becomes the liquid metal of choice, in comparison to other liquid metals, because in addition to the low $Z$ considerations, it has a wide range of working temperatures $\left(181^{\circ} \mathrm{C}-1342^{\circ} \mathrm{C}\right)$, low vapor pressure $\left(10^{-7} \mathrm{~Pa}\right.$ at $200^{\circ} \mathrm{C}$, only $\mathrm{Ga}$ and Sn are lower), and it has the lowest pumping power requirement because of its low density, high heat capacity, and low viscosity.

\section{Engineering Issues}

Few materials are compatible with liquid lithium; it dissolves metals including $\mathrm{Cu}, \mathrm{Ag}, \mathrm{Au}, \mathrm{Ni}$ [6]. A Cu gasket lost $41 \%$ of its mass in less than 4 hours of operation causing a major vacuum leak during shakedown of the windowless Li target system. Li also dissolves ceramics, glasses, concrete, and organics. However, liquid lithium systems can be fabricated from stainless steel, Fe, Ta, Ti, Mo, Nb, vanadium alloys, and Be [6], [7], [8].

Metal-to-metal seals, suitable for both pressure and high vacuum, are necessary for liquid alkali metals in these applications. Welded connections are most desirable. Four mechanical joint designs can be used, 
1) Grayloc ${ }^{\circledR}$ flanges with 17-4 PH SS seal rings,

2) Conflat flanges with soft iron gaskets,

3) Hollow SS o-rings with high polish surface finish, and

4) Cajon ${ }^{\circledR}$ flanges with SS gaskets.

Containment objectives include preventing water from contacting any lithium in the system and preventing air from contacting hot, molten lithium. Primary containment should be fabricated from proper materials; secondary containment is essential. Ideally, the secondary should be a sealed containment, enclosing primary vessel, with inert gas backfill, maintained at a temperature below the melting point of lithium. At a minimum, it should provide containment of any liquid lithium spills and splashes, with a negative pressure air flow through an aerosol removal system. In some designs, the vacuum system of the beamline serves as part of the secondary containment.

A multiple zone heating system, utilizing ceramic band heaters, provides for easy installation of heaters and accurate control of system temperature distribution while minimizing hot spots which could result from significant differences in metal mass from component to component. Details of the heating system are discussed in a later section.

Permanent magnet, DC electromagnetic (EM) pumps are used on the RIA windowless Li target and the ANL/MSU adjustable thickness Li/Be target for the NSCL [9]. These pumps are simple in design and construction, reliable, and inexpensive. Despite these advantages, these types of pumps had not been favored in the early days of liquid metal technology development because the necessary high current, low voltage power supplies were not readily available. Today however, due largely to the development and common use of superconducting magnet systems, suitable power supplies are easily obtainable and affordable. Proper performance of both DC EM pumps and DC EM flow meters require that the duct walls be wetted by bringing the duct and $\mathrm{Li}$ into contact, then raising their temperature to $450{ }^{\circ} \mathrm{C}$ for 15 minutes [10]. To assure good contact between the $\mathrm{Li}$ and the duct surfaces, the wetting procedure should be performed under vacuum. Pump performance under vacuum conditions does not appear to be markedly different from that under ordinary conditions, but this issue is still under investigation. Details of the actual DC EM pump and EM flow meter used in this study are described in a later section.

\section{Safety Issues}

Lithium is the least reactive of all alkali metals, nonetheless, liquid lithium is very reactive. The most violent reactions occur with water, water vapor, organics, and fluorocarbons. Lithium reacts slowly with oxygen and nitrogen. $\mathrm{H} 2$, which is explosive in concentrations between $4 \%$ and $74.2 \%$ in air, is evolved from water and many organic reactions with $\mathrm{Li}$. $\mathrm{Li}_{3} \mathrm{~N}$ violently decomposes on contact with moisture. 
In dry air, the potential for $\mathrm{Li}$ fire exists only when lithium is molten at a temperature greater than $400{ }^{\circ} \mathrm{C}$. In very moist air, fire has been reported to occur at temperatures as low as $200{ }^{\circ} \mathrm{C}$. Potential for fire suggests that a fire/safety watch be present when opening a lithium filled system for experimental modification, maintenance or any task requiring Li exposure to air or water. Graphite and powdered carbon (Lith-X) are the most popular effective extinguishing agents. Additional operational safety considerations include properly trained personnel, continuous monitoring of experimental systems when Li is flowing, and slowly increasing pump current when establishing flow to avoid splashing at startup. Heater coverage should approach $100 \%$ to eliminate cold spots. Place TCs at suspected cold spots in addition to heater controls/monitors. Heat system reservoirs prior to internal passages (starting at free surfaces) to eliminate expansion problems ( $\sim 1.5 \%$ volume expansion upon melting). Add lithium to a cold system if possible, solid $\mathrm{Li}$ tends to stick to hot surfaces.

Decontamination and cleaning of lithium containing components should be accomplished at room temperature using eye protection and gloves. Water is the easiest and simplest cleaning agent, used in a hood or ventilated glove box like enclosure. In this setting, only small, 10 g quantities of Li per event should be treated. Roughly $500 \mathrm{ml}$ of water per gram of $\mathrm{Li}$ is needed to avoid excessive heat generation. Complete disassembly of components is necessary, as water will not penetrate cracks and crevices to react $\mathrm{Li}$ to $\mathrm{LiOH}$. The ph of the resulting $\mathrm{LiOH}$-water solution is quite basic, thus further treatment is required prior to disposal.

\section{Summary}

Liquid lithium targets appear very promising for future high power target applications. The technical and engineering issues are well understood, including the thermal-hydraulics, and liquid metal pump performance. Alkali metal safety issues are well understood and, if carefully applied, will result in safe, reliable operation.

\section{Heat Deposition in a Lithium Jet by an E-Beam}

\section{Description of the Model Used}

The MCNPX [11] Monte Carlo transport code was used to simulate the interaction of electron beams with the lithium jet. The energy deposition profile inside the jet was scored in small volumes and used as input for the Origin [12] graphic program to display the information. The geometry was divided in 3300 meshes with $0.1 \mathrm{~mm}$ increments in the radial direction and $0.3 \mathrm{~mm}$ increments in the axial direction. The total thickness of the jet was assumed to be $1 \mathrm{~cm}$ and the beam footprint on the jet was modeled as uniformly distributed in a 1-mm diameter area.

\section{Results}

The calculations were performed on one-source particle basis and the heat deposition calculated in terms of MeV's per source particle. Three different electron beam energies were simulated: 1,3 , and $5 \mathrm{MeV}$. The objective of the calculations was to 
determine if a uniform energy deposition profile across the lithium jet could be obtained and how close it would be to the expected uranium beam energy deposition profile. Also, the maximum energy deposition was of critical interest because of a concern that an instability in the jet may be caused by the maximum energy deposition.

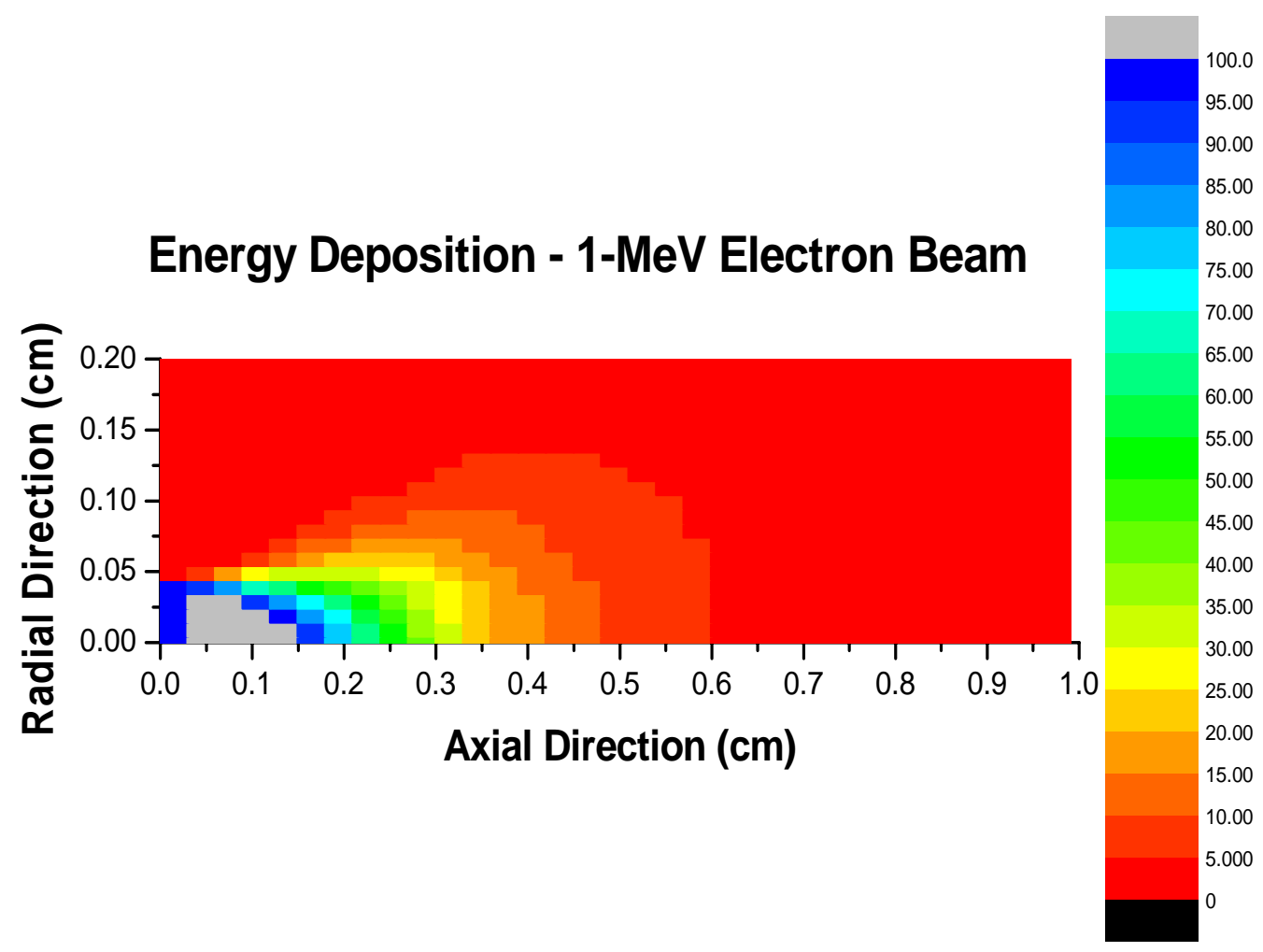

Figure 4. Energy deposition profile in $\mathrm{MeV} / \mathrm{cm}^{3}$ along the thickness of the beam for a $1 \mathrm{MeV}$ electron beam incident on a fast-flowing lithium jet.

Figure 4 displays the energy deposition $\left(\mathrm{MeV} / \mathrm{cm}^{3}\right)$ in the lithium jet for a 1-MeV electron beam. The calculation was performed assuming cylindrical symmetry for the energy deposition around the beam axis. Table 1 presents the numerical values of the energy deposition for some selected positions. As it can be seen, the 1-MeV electron beam loses almost all its energy along the first half of the lithium jet thickness. At $5 \mathrm{~mm}$ inside the jet, the energy deposition is already reduced by more than one order of magnitude. The peak energy deposition, at positions close to the strike point of the beam on the jet, is about $103 \mathrm{MeV} / \mathrm{cm}^{3}$ per incident electron (that translates to $4.12 \mathrm{MW} / \mathrm{cm}^{3}$ for a $40-\mathrm{kW}$ power electron beam). The calculated total energy deposited into the jet per incident electron is $0.997 \mathrm{MeV}$, meaning that basically all energy carried by the beam is deposited into the jet. This represents that for a $40 \mathrm{~mA}$ electron beam about $40 \mathrm{~kW}$ will be deposited into the beam. The peak energy deposition of about $100 \mathrm{MeV} / \mathrm{cm}^{3}$ is similar to that expected for a uranium beam hitting the lithium jet in the fragmentation target design. 


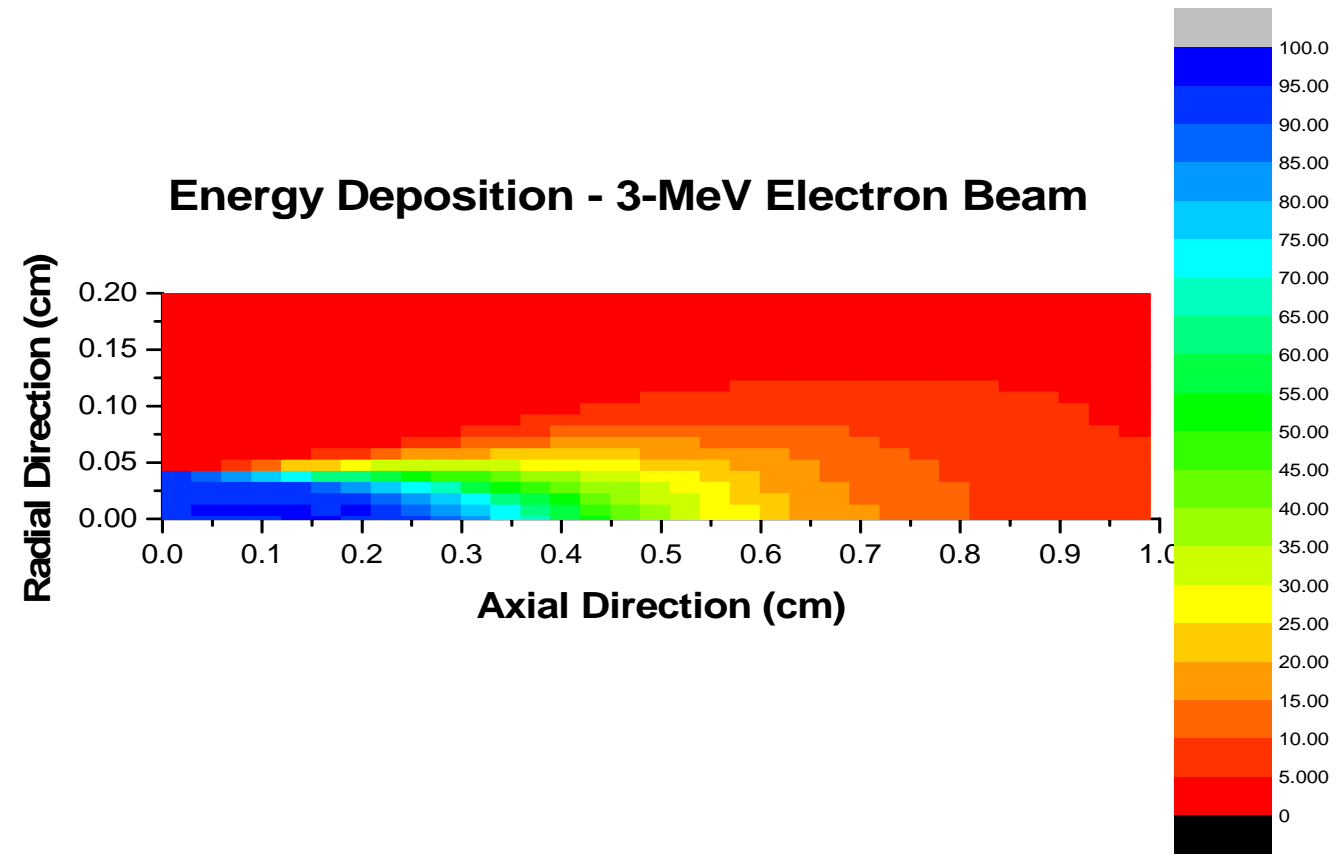

\section{Figure 5. Energy deposition $\left(\mathrm{MeV} / \mathrm{cm}^{3}\right)$ profile for a 3-MeV electron beam incident on a fast-flowing lithium jet.}

Figure 5 presents the results for the $3-\mathrm{MeV}$ electron beam case. The model used in this calculation was the same as the one used for the $1-\mathrm{MeV}$ electron beam case except for the electron beam energy. Table 2 presents the numerical values of the energy deposition for some selected positions. As it can be seen, the 3-MeV electron beam is not "stopped" inside the lithium jet. The beam, when exiting the lithium jet, is still depositing 5-MeV/cm ${ }^{3}$ per electron while the peak energy deposition at positions close to the beam entrance is about $95 \mathrm{MeV} / \mathrm{cm}^{3}$. The calculated total energy deposited into the jet per incident electron is $0.823 \mathrm{MeV}$, meaning that $27.4 \%$ of the energy carried by the beam is deposited into the jet. This indicates that, considering a $40-\mathrm{kW}$ electron beam, about $11 \mathrm{~kW}$ will be deposited into the beam and $29 \mathrm{~kW}$ will have to be stopped some place else. This translates into some shielding requirements to stop the beam and to avoid excessive dose rates in equipment and possibly personnel in the vicinity of the experiment. The peak energy deposition was calculated to be about $95 \mathrm{MeV} / \mathrm{cm}^{3}$ which is comparable to that expected for a uranium beam hitting the lithium jet in the fragmentation target design. A noticeable difference between the $3-\mathrm{MeV}$ and $1-\mathrm{MeV}$ cases is that, due to its higher energy, the $3-\mathrm{MeV}$ beam scatters much less than the 1$\mathrm{MeV}$ case and its path inside the jet is more confined than the $1-\mathrm{MeV}$ case. This characteristic of the $3-\mathrm{MeV}$ beam produces a profile more similar to the one expected from a uranium beam. 


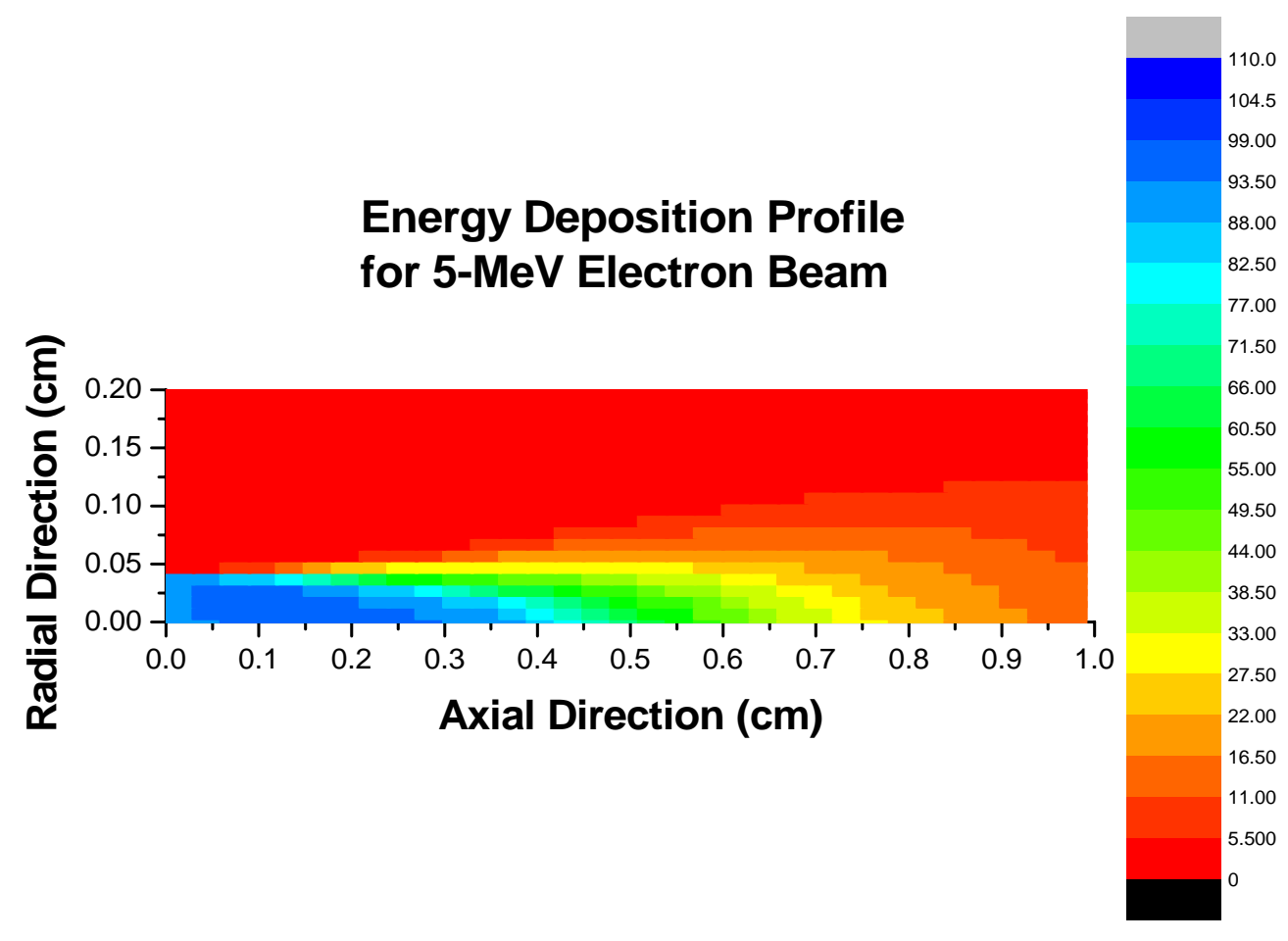

Figure 6. Energy deposition $\left(\mathrm{MeV} / \mathrm{cm}^{3}\right)$ profile for a 5-MeV electron beam incident on a fast-flowing lithium jet.

Figure 6 presents the results for the $5-\mathrm{MeV}$ electron beam case. The model used in this calculation was the same as to the one used for the 1- and 3-MeV electron beam cases, except for the beam energy. Table 3 presents the numerical values of the energy deposition for some selected positions. As can be seen, the 5-MeV electron beam is not "stopped" inside the lithium jet and it is still depositing about $15-\mathrm{MeV} / \mathrm{cm}^{3}$ after 1 - $\mathrm{cm}$ of lithium. The peak energy deposition is about $93 \mathrm{MeV} / \mathrm{cm}^{3}$ at positions close to the entrance of the beam into the jet. This peak energy deposition is lower than both, the 1 and the 3-MeV beams. The calculated total energy deposited into the jet per incident electron is $0.804 \mathrm{MeV}$, meaning that only $16.1 \%$ of the energy carried by the beam is deposited into the jet. Considering a $40-\mathrm{kW}$ electron beam, only about $6.4 \mathrm{~kW}$ will be deposited into the beam and $33.6 \mathrm{~kW}$ will have to be collected someplace else. Again, this will imply in use of shielding for protecting equipment and possibly personnel. The maximum energy deposition of about $100 \mathrm{MeV} / \mathrm{cm}^{3}$ is similar to that expected for a uranium beam hitting the lithium jet in the fragmentation target design. The 5-MeV electron beam has the most confined path inside the lithium jet among the beams considered, making it the most similar to the expected energy deposition profile of a uranium beam. However, the relatively low percentage of energy deposited in the jet presents a considerable disadvantage for this case. 


\section{Conclusions}

The calculations indicated that there is no real gain in increasing the energy of the beam beyond $1 \mathrm{MeV}$ because the total amount of energy deposited in the jet remains about the same. The energy deposition of the $1-\mathrm{MeV}$ electron beam is much more concentrated in the first tenths of a millimeter into the jet than the other cases. The amount of energy escaping from the lithium jet is much larger in the higher energy cases. The 3- and 5-MeV cases have a more confined energy deposition in the direction of the beam, and less scattering. The 1-MeV electron beam may present the best approach to simulate the energy deposition, due to its compactness in terms of energy deposition profile and the advantage of having the beam stopped inside the lithium jet. Also, the 1$\mathrm{MeV}$ electron beam presents the highest overall energy deposition.

The 1-MeV electron beam, despite its imperfect match of the energy deposition profile, provides a similar maximum energy deposition. Considering that the maximum energy deposition density is one of the most likely causes to produce any jet disturbance, it was concluded that experimental simulation using electron beams would be a valuable tool to assess beam-jet interaction, e.g. thickness, uniformity, and stability. Using electron beams to simulate uranium beam energy deposition has the additional advantageous feature that negligible residual radiation remains after shutdown of the beam.

\section{A $20 \mathrm{~kW}$ Beam-on-Target Test of a High-Power Liquid Lithium Target for RIA}

\section{Description of Beam-on-Target Setup}

The experimental setup consisted of the windowless lithium target loop, beamline, and Dynamitron electron-beam accelerator as shown in Figure 7. A high-power, 1-MeV Dynamitron was leased from Radiation Dynamics Inc. (RDI) to demonstrate that power densities equivalent to a 200-kW RIA uranium beam, deposited in the first $4 \mathrm{~mm}$ of a flowing lithium jet, can be handled by the windowless target without disrupting either the $5 \mathrm{~mm} \times 10 \mathrm{~mm}$ flowing lithium jet target or the beamline vacuum. Heat loads up to 20 $\mathrm{kW}$ were deposited by a $1 \mathrm{~mm}$ diameter up to $20 \mathrm{~mA}$ beam of $1-\mathrm{MeV}$ electrons from the Dynamitron, which was connected to the loop with the beamline in which the electron beam is delivered to the liquid lithium jet. The beamline was maintained under vacuum at $<10^{-6}$ Torr using turbomolecular and diffusion pumps. There were two 5 degree bends in the beamline to prevent any lithium droplets or vapor from entering the Dynamitron accelerator in the event of lithium jet splashing or disruption. The beamline also had horizontal and vertical steering electromagnets to control the beam path at each bend. Gate valves were located at each end of the beamline to isolate the Dynamitron accelerator and the lithium loop in case of off-normal events or maintenance. 


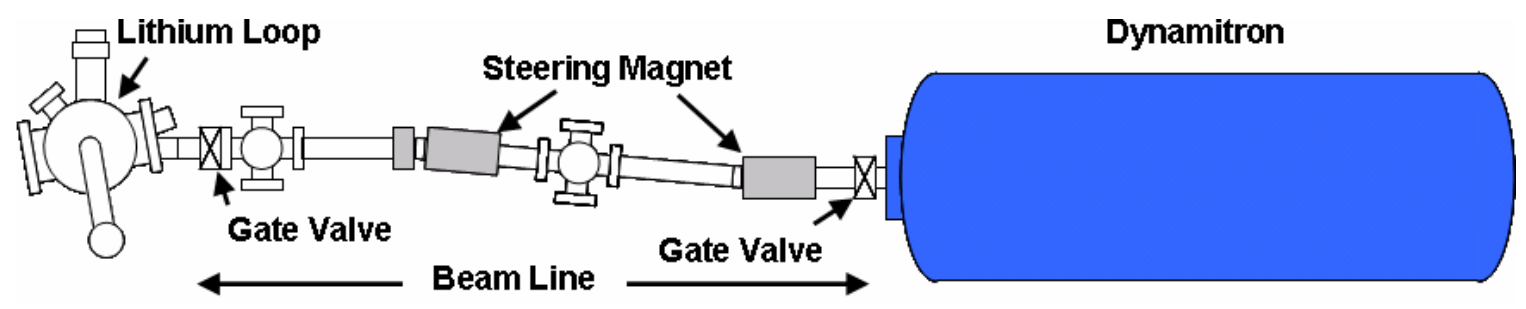

Figure 7. Schematic Top View of Experimental Layout.

The windowless lithium target system discussed in the previous section (see Figure 2) was modified to increase the lithium inventory to 6 liters so high power tests could be run in a heat-sink mode (Figure 8). The loop had an Ar gas supply as well as a diffusion pump, which was capable of maintaining the loop at $<2 \times 10^{-4}$ Torr. This setting allows the loop to be under either Ar or vacuum; however, the loop was usually kept under vacuum. A nozzle with an opening size of $5 \mathrm{~mm}$ in width and $10 \mathrm{~mm}$ in depth was located in the vacuum chamber downstream of the EM flow meter (Figure 8). A free jet of liquid lithium simulating the windowless target was formed at the exit of the nozzle (Figure 3). Sixteen ceramic band heaters with a total of $17,625 \mathrm{~W}$ at $208 \mathrm{~V}$ were attached to the loop to control the temperature. These heaters were connected in five groups, forming five independent zones around the loop, and each zone had its own Athena programmable temperature controller. Each temperature controller had a dedicated, surface mounted, type-K, TC to control the temperature of each zone. A DC EM pump located at the bottom of the loop, as shown in Figure 8, was used to circulate the liquid lithium. The EM pump had a pair of permanent magnets $(0.746 \mathrm{~T})$ on the top and bottom of the pump ducts. The pump ducts were constructed from stainless steel and directly welded to the loop to minimize the potential for a leak. Two copper electrodes were brazed, one to each side of the pump, and a programmable DC power supply $(10 \mathrm{~V} \times$ 1000 A) provided DC current to the pump.

\section{Instrumentation and Data Acquisition}

The applied voltage across the pump was monitored. The pump current was also monitored by means of measuring the voltage drop across a shunt resistor connected in series with the power supply. Lithium flow rate was measured via a DC EM flow meter previously calibrated in sodium. The EM flow meter is positioned in the loop at the downstream of the EM pump (see Figure 8). The EM flow meter consists of a $0.086 \mathrm{~T}$ permanent magnet and 1 inch schedule 40 stainless steel piping with two electrodes. The flow rate was obtained by measuring the voltage across these two electrodes of the flow meter. However, since the magnetic field created by the flow meter magnet disturbed beam focusing, the magnet was removed and the flow meter was not used during beamon-target experiments. For better contact with liquid lithium, both EM pump and flow meter were wetted by heating to $450{ }^{\circ} \mathrm{C}$ as discussed in an earlier section. Using the flow meter, the volumetric flow rate of lithium and the jet velocity at the nozzle were determined as a function of the pump current as shown in Figure 10. 


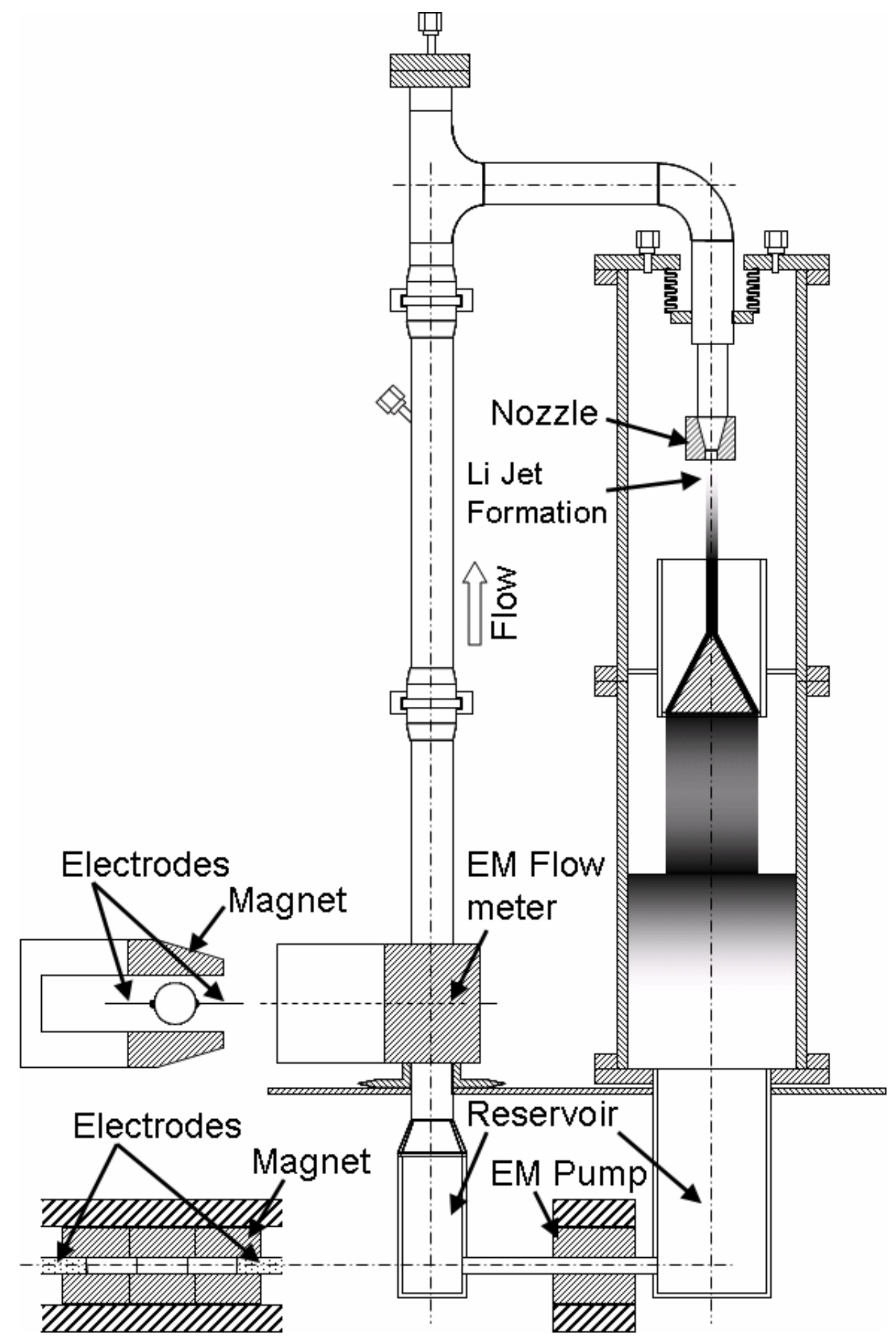

Figure 8. Schematic side view of lithium loop. The overall height of the loop is $0.9 \mathrm{~m}$. 


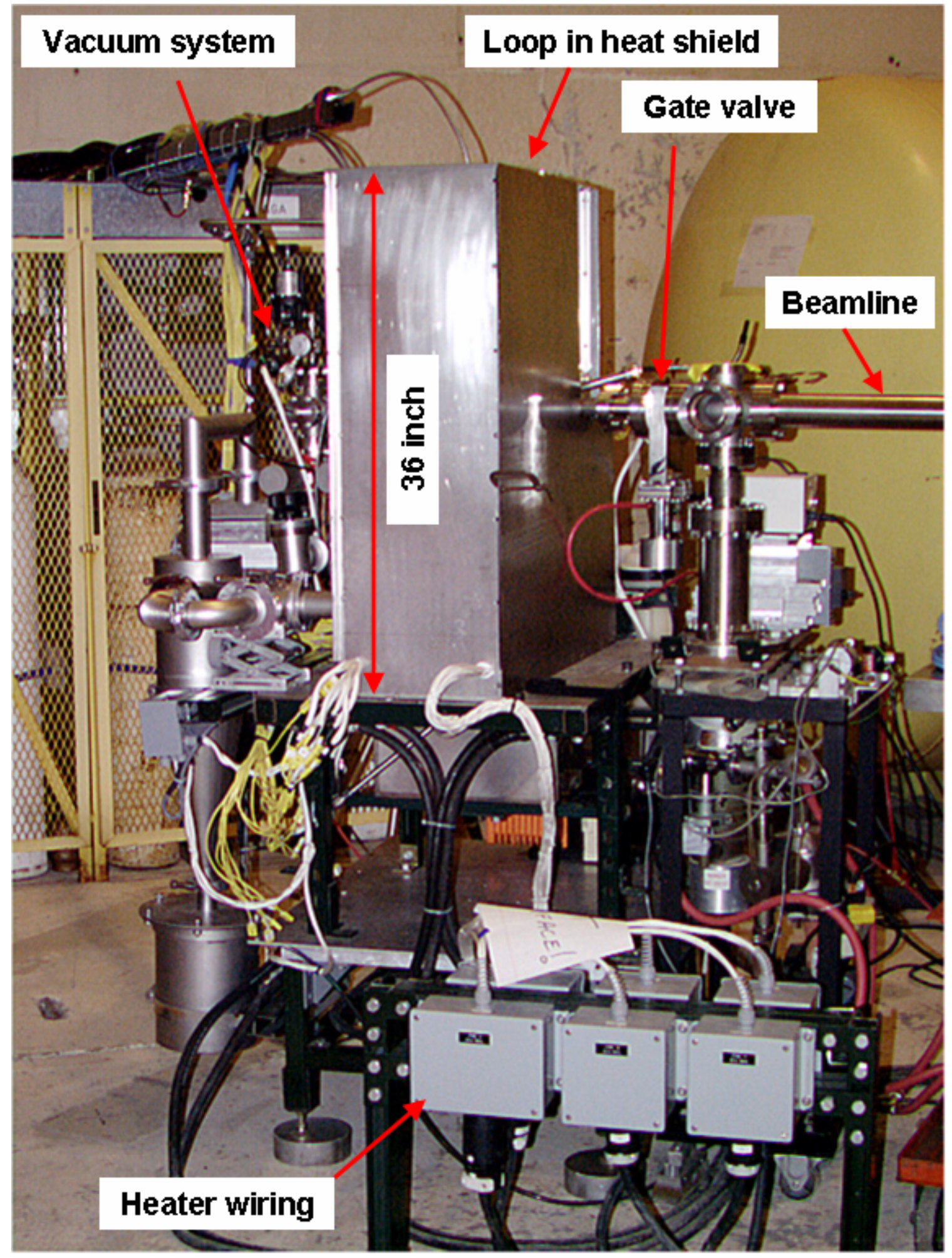

Figure 9. Photo of windowless target system. 


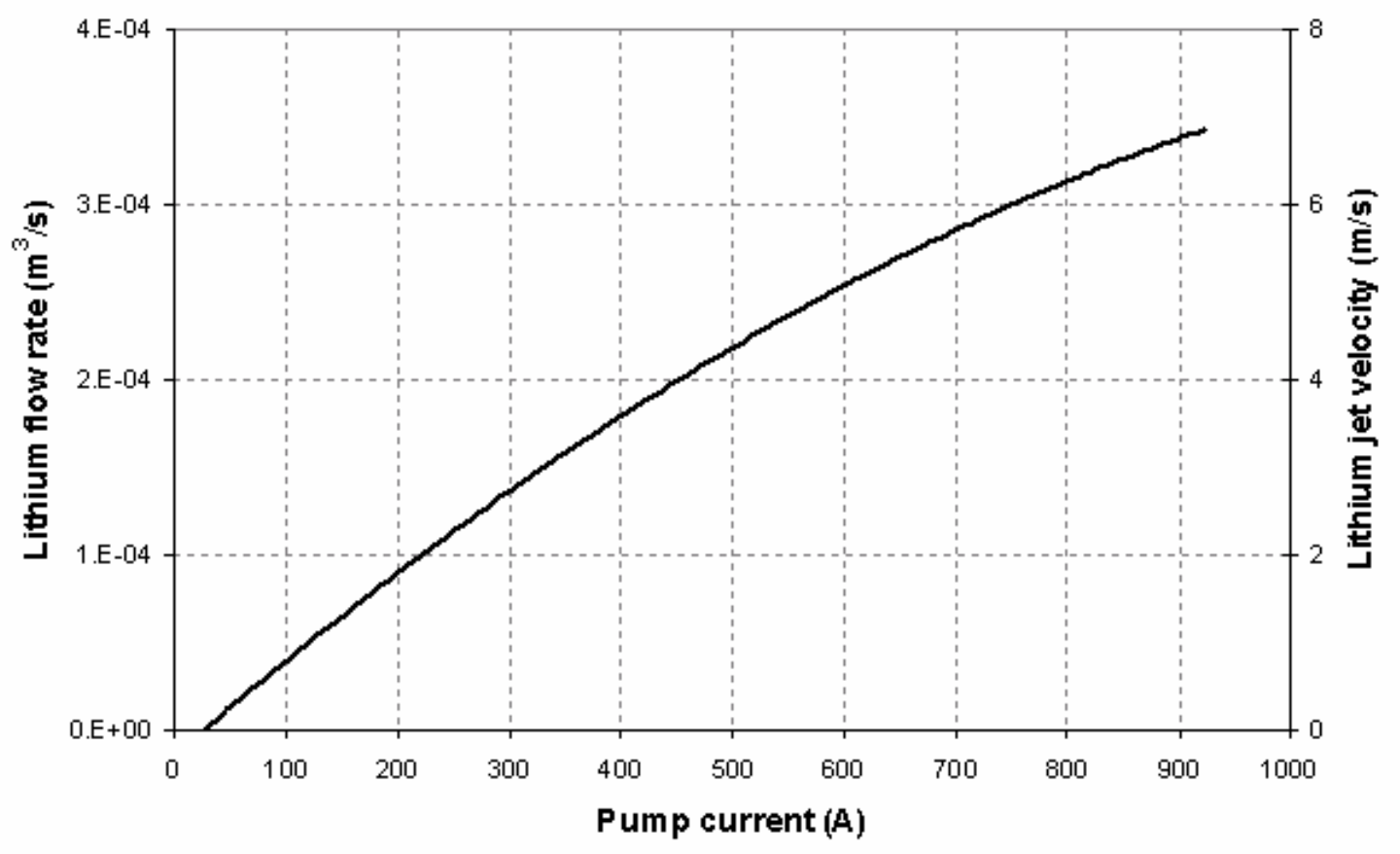

Figure 10. Calibration curve for the volumetric flow rate and the jet velocity.

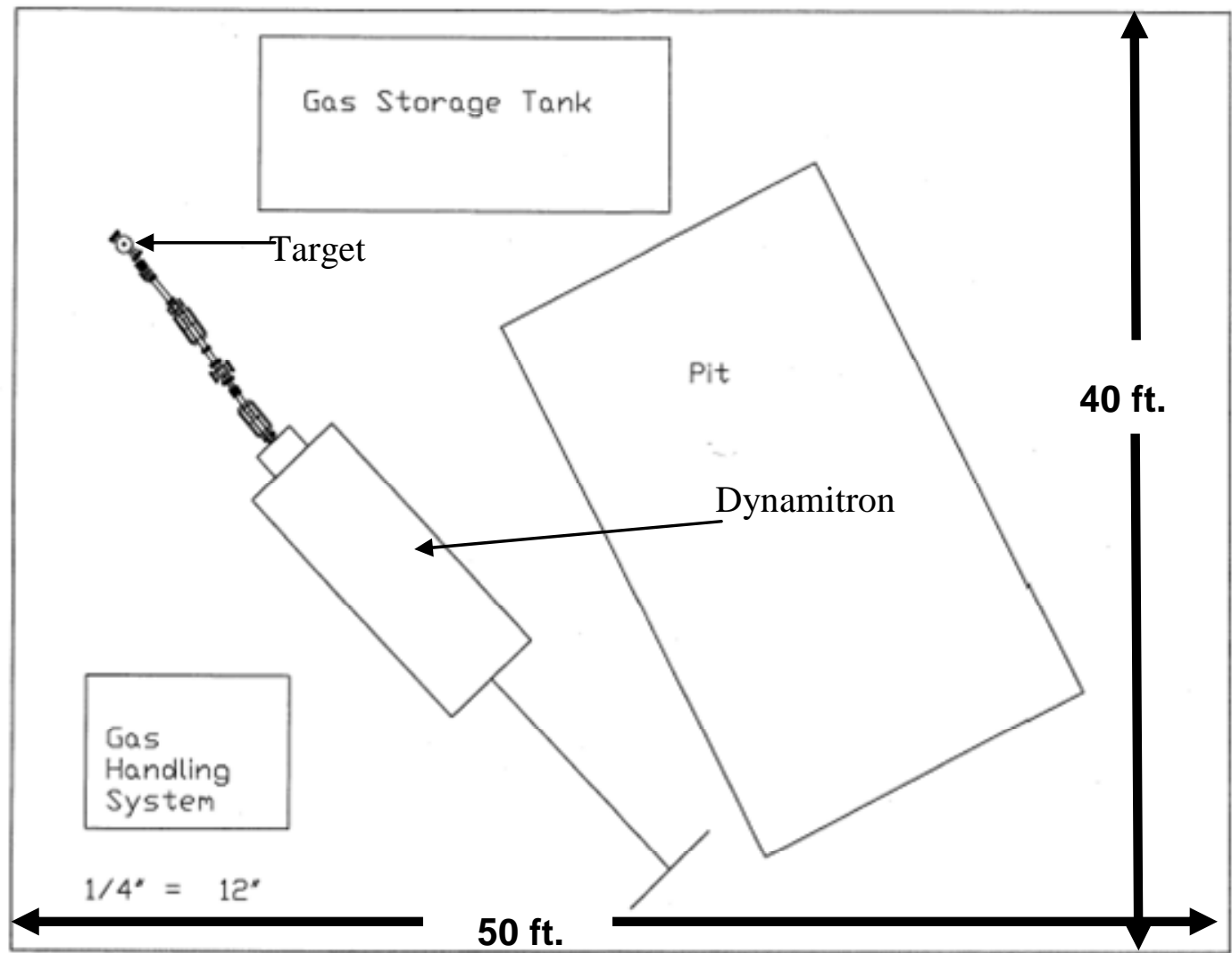

Figure 11. Floor plan layout for $20 \mathrm{~kW}$ beam-on-target test in BLDG. 211 at ANL. 
A stand-alone secondary containment and dry scrubber system were integrated into the system, to permit testing in a nuclear physics laboratory setting, shown in Figure 9. The modified target system and all supporting subsystems, such as vacuum, heating, instrumentation, and data acquisition were first tested as a unit and then moved to a highbay vault with 7 -ft. thick concrete walls, to obviate the need for additional radiation protection, as personnel were excluded from the vault during accelerator operations. The experimental setup was remotely controlled from outside the room. The vault floor plan layout for the $20 \mathrm{~kW}$ test is shown in Figure 11.

The lithium system was instrumented with 20, type-K monitoring TCs attached at various locations, including the EM pump ducts, EM pump magnets, and the EM flow meter magnet. One of these monitoring TCs was sheathed and could be inserted in the flowing lithium jet during the experiments by means of a remotely controllable traversing mechanism. Also, a fixed, sheathed thermocouple was inserted into the sidewall of the riser pipe measuring the bulk lithium temperature at that point. All monitoring TCs were connected to a Yokogawa chart recorder for data collection. The pressures at the various locations of the loop were monitored by capacitance pressure transducers and thermocouple gauges. In addition, a commercially available high temperature liquid metal pressure transducer from Gefran was installed at the top of the riser tube to measure the pump discharge pressure. The pressure data and the voltages across the EM pump, flow meter, and the shunt resistor connected in series with the power supply were monitored by a National Instrument (NI) data acquisition (DAQ) Card. The NI DAQ card was attached to a laptop PC, which also collected temperature data from the chart recorder via a General Purpose Interface Bus (GPIB). Data acquisition was controlled by a LabVIEW program.

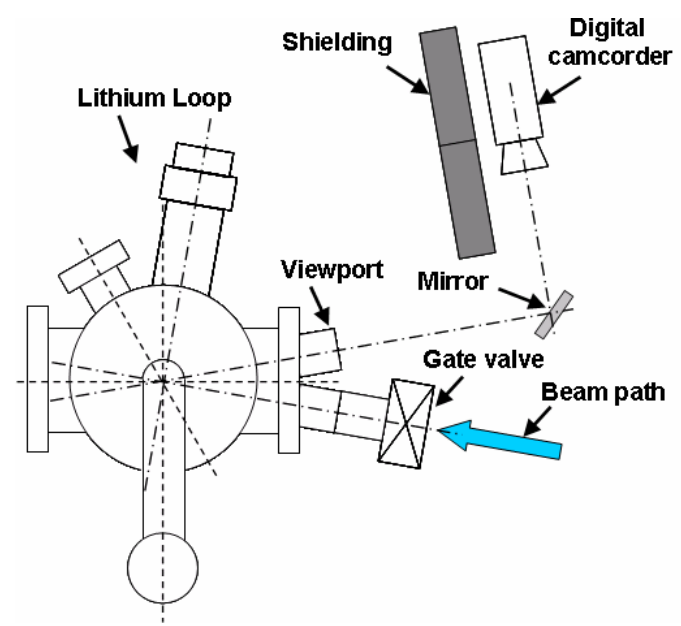

Figure 12. Schematic Top View of Detailed Setup near the Loop.

Since the high level of X-ray during the experiments did not permit a direct visual observation of the lithium jet, a remotely controlled digital camcorder was employed to record and monitor visual images of the lithium jet through a viewport attached to the loop near the nozzle (Figure 12). Two types of window material were used; quartz and sapphire. Of the two, sapphire has better IR transmission. Depending on the beam 
power, the quartz window showed brown discoloration from X-ray irradiation. To shield the camcorder from direct X-ray exposure, the visual images were reflected at right angles using a front-surfaced mirror located near the viewport, allowing several lead bricks to be placed between the camcorder and the loop, where the X-rays were generated by electron beam bombardment on the lithium jet (or the surrounding stainless steel structures in case of miss-steering the beam). This optical setup was replaced with an IR camera, gold-plated mirror, and telescope to observe IR images of the lithium jet for measuring the surface temperature distribution of the jet.

\section{Experimental Procedure}

The Dynamitron, beamline and lithium target system are normally kept under vacuum, 24/7. The Dynamitron had to undergo voltage conditioning each day.

A typical experiment started by heating the loop to around $220{ }^{\circ} \mathrm{C}$. After all temperatures along the loop were stabilized, the pump current was increased slowly. The lithium jet was usually formed when the pump current reached around $50 \mathrm{~A}$. The formation of the jet was confirmed visually through the viewport. After the jet was established, the Dynamitron accelerator was turned on for electron beam irradiation at low power. The beam spot appeared as a white-blue dot on the lithium jet. The spot diameter was controlled via a focusing coil about $1 \mathrm{~m}$ from the target. A beam diameter of 1 to $1.5 \mathrm{~mm}$ was used during the high-power tests. The location of the beam spot relative to the jet was carefully adjusted by changing the current to the two steering magnets. Once the location of the beam spot was set, the digital camcorder started recording visual images and the beam power was increased to the desired level. The temperatures, pressure, and other voltage signals including the pump current and voltage, were recorded every one second during the experiment. These recorded visual images as well as temperatures, pressure, and voltages form the basis of the present work.

\section{Results}

Preliminary experiments were conducted at low beam powers to ensure the stability of the lithium jet during beam irradiation. After confirming the stable operation of the jet with low-power beams, a series of experiments at increased beam powers of up to $20 \mathrm{~kW}$ was performed. Since there was no heat exchanger in the loop, the deposited thermal energy accumulated within the loop, increasing the bulk lithium temperature. Such temperature increases limited continuous operation of the loop at a high beam power. Therefore, the duration of each run at a high beam power was typically limited to a few minutes. For example, Figure 13 shows the history of measured temperatures at the nozzle and the splash shield and background pressure in the loop while the beam power was increased to $15 \mathrm{~kW}$ over approximately 3 minutes. The splash shield was located below the nozzle where the jet was caught and its temperature reflected the actual temperature of the bulk lithium heated by the beam. The pump current was maintained at $400 \mathrm{~A}$ at which the estimated jet velocity was about $3.6 \mathrm{~m} / \mathrm{s}$ (see Figure 10). The maximum temperature measured at the splash shield and the nozzle reached $270{ }^{\circ} \mathrm{C}$ and slightly above $260{ }^{\circ} \mathrm{C}$, respectively. It must be noted that because some beam energy was emitted as X-rays and absorbed by surrounding structures, temperatures kept increasing, 
even after the beam was shut off, while energy stored in the surrounding structures was released. The observed increases in the background pressure were as high as $\sim 0.9$ mTorr (from 0.5 to 1.4 mTorr) during the experiment.

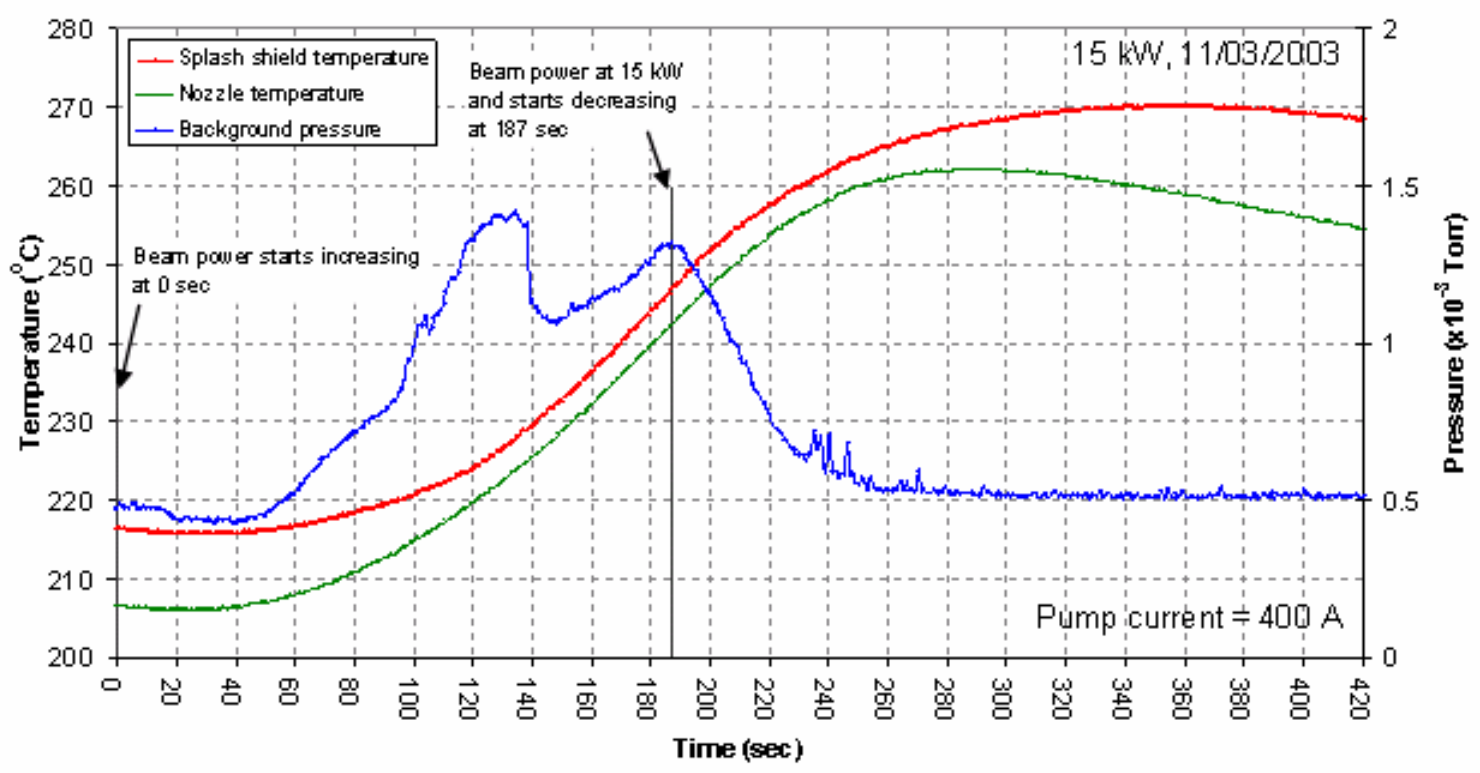

Figure 13. Temperature and Pressure during $15 \mathrm{~kW}$ Test.

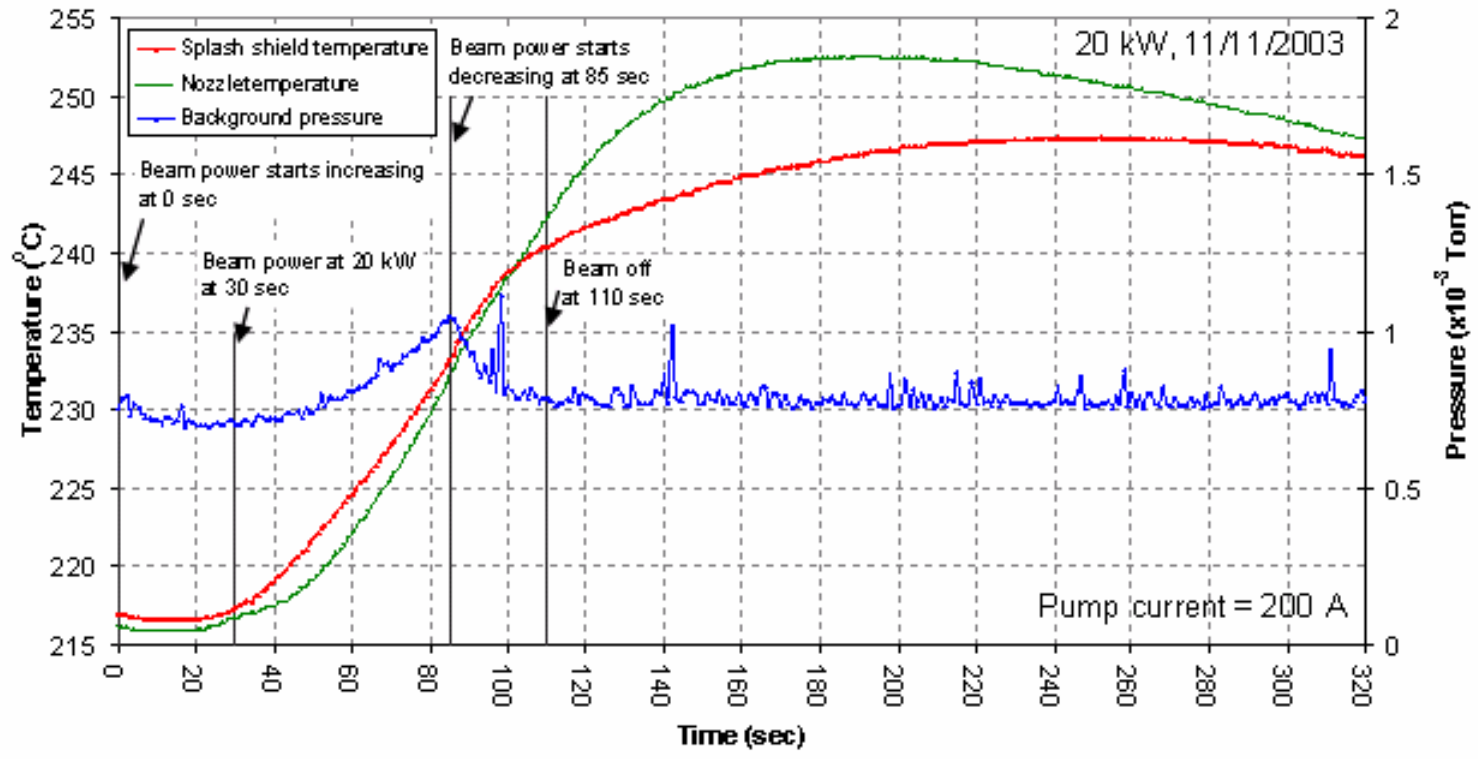

Figure 14. Temperature and Pressure during 20 kW Test.

Figure 14 shows the history of measured temperatures at the nozzle and the splash shield, and background pressure taken at the highest beam power of $20 \mathrm{~kW}$. The pump current was kept at $200 \mathrm{~A}$, at which the estimated jet velocity was about $1.8 \mathrm{~m} / \mathrm{s}$ (see Figure 10). The beam power was increased quickly (20 kW over $\sim 30$ seconds) to 
minimize the temperature rise in the system. As a result, a steady beam power of $20 \mathrm{~kW}$ was achieved for about 55 seconds. A steady, 55 seconds run at $20 \mathrm{~kW}$ resulted in a temperature rise of $\sim 30{ }^{\circ} \mathrm{C}$ in bulk lithium temperature. The observed increase in pressure was only $\sim 0.3$ mTorr (from 0.8 to $1.1 \mathrm{mTorr}$ ) during the experiment. This pressure increase is considered mostly due to outgassing of the vacuum chamber components, since the vapor pressure of $\mathrm{Li}$ at $250{ }^{\circ} \mathrm{C}$ is $3.4 \times 10^{-8}$ Torr $\left(4.5 \times 10^{-6} \mathrm{Torr}\right)$.
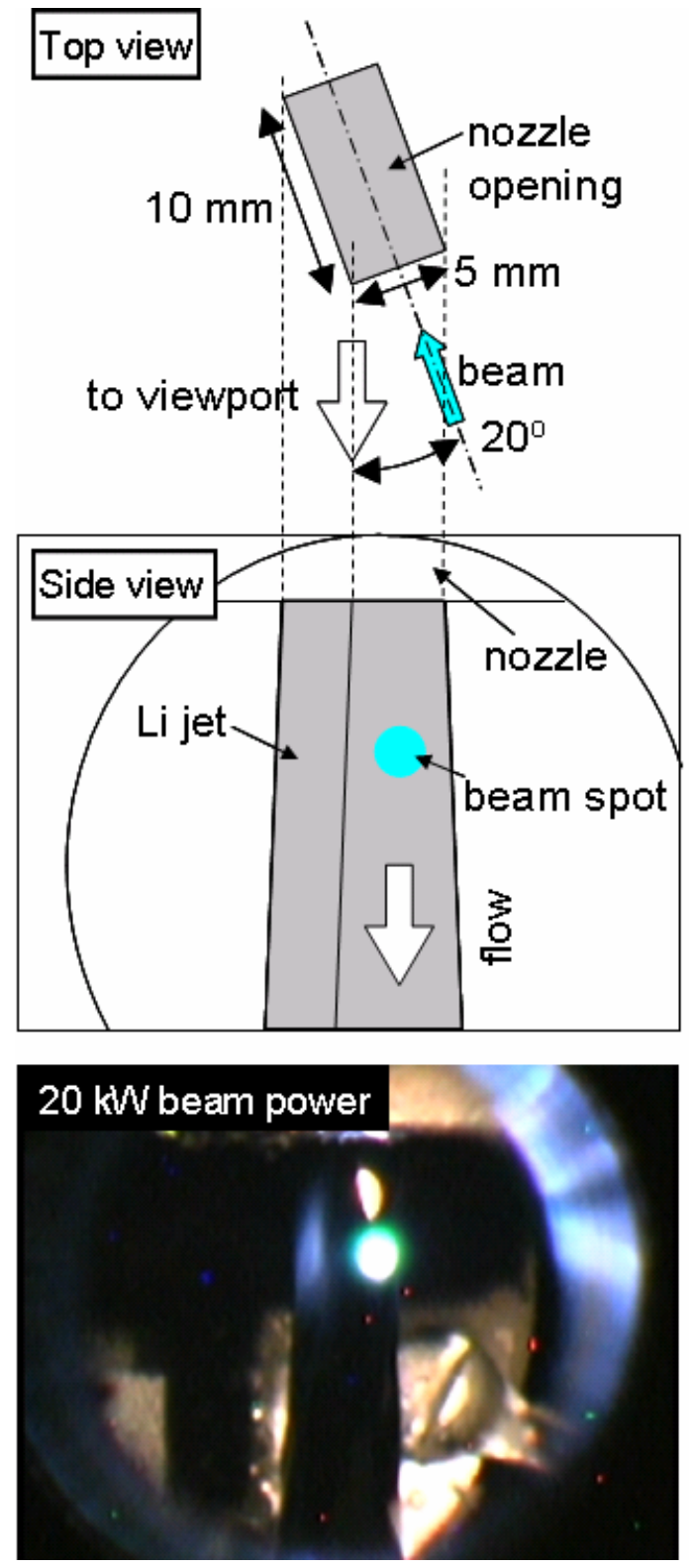

Figure 15. Schematic of Nozzle, Jet, and Beam and Actual Image of Jet at 20 kW Beam Power.
Figure 15 shows the relative location of the jet and beamline, as well as, the actual image, which correspond to the experiment shown in Figure 14. It must be noted that the image is a mirror image, because it was reflected by the mirror once (see Figure 12). This image shows stable operation of the liquid lithium jet under an extreme thermal load of $20 \mathrm{~kW}$. All other images recorded at various beam powers showed similar results as this figure, confirming stable flow of the jet under thermal loads of up to $20 \mathrm{~kW}$. For the beam diameter used in this experiment, the total power deposited in the $1 \mathrm{~cm}$ thick lithium jet and the power density in the jet were equivalent to those of a 200 $\mathrm{kW}, 400 \mathrm{MeV} / \mathrm{u}$ uranium beam of the same diameter.

In addition to visual observations, attempts to measure the spatial temperature distribution of the jet were made using a traversing TC as well as an IR camera. Figure 16 shows the temperature measured by the traversing TC and corresponding images. Figure 16 (1) is an image taken while external visible light illuminated the jet and shows the initial location of the traversing TC that was inserted in the jet. The tip of the TC shown on the right of the jet in the image [Figure 16 (1)] was outside of the jet. As the beam power increased, the temperature reading increased. Because scattered electrons and emitted X-rays from the beam spot 

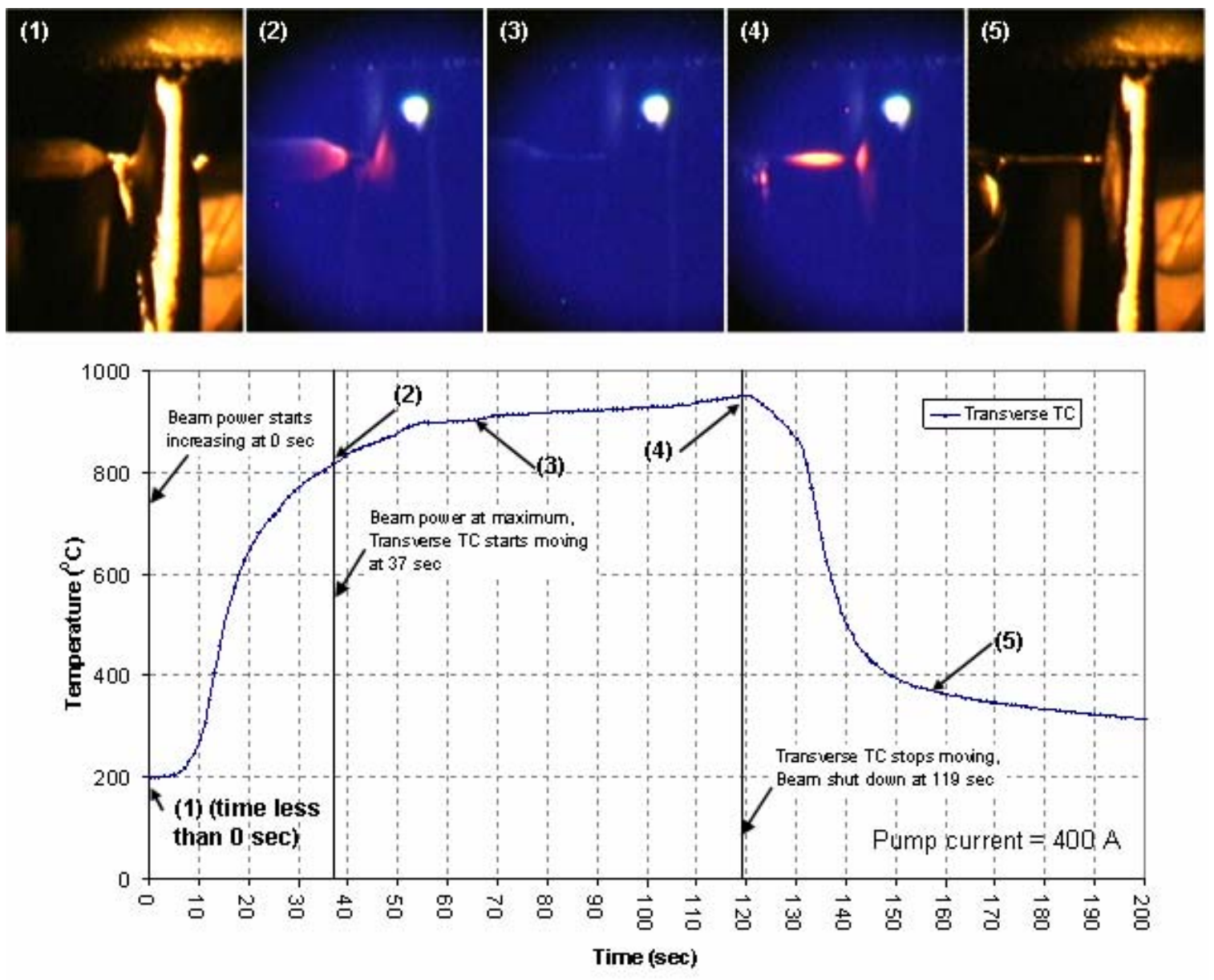

\section{Figure 16. Recorded Temperatures Measured at Transverse Thermocouple and Corresponding Images.}

heated up the junction in the TC sheath, it was doubtful that the TC readings reflected the actual lithium jet temperature. For example, Figure 16 (2) shows that a red glowing spot occurred at the sheath that was outside the lithium flow. The sheath close to the lithium flow was not glowing, implying that the bulk lithium was cooler than the TC and was cooling the TC. Again, Figure 16 (4) shows that the TC tip that was touching the surface of the jet was cooler than the glowing part of the sheath. Figure 17 shows the nozzle and splash shield temperatures and the background pressure during the same experiment. Although the readings at the traversing TC in the jet indicated a very high temperature ( $900{ }^{\circ} \mathrm{C}$ ) in Figure 16, the nozzle and the splash shield temperatures did not exceed $225{ }^{\circ} \mathrm{C}$ during the experiment.

When it was attempted to use an IR camera to measure the surface temperature of the jet, the apparent temperature of the jet surface was lower than the melting point of lithium $\left(181^{\circ} \mathrm{C}\right)$. Since the surface of the liquid lithium has very high reflectivity, it reflected the surrounding emission very well and it is likely that most of the emission captured by the IR camera was not the emission from the lithium jet itself, but that from 
the surrounding structures, making it impossible to reasonably measure the surface temperature of the lithium jet itself using an IR camera.

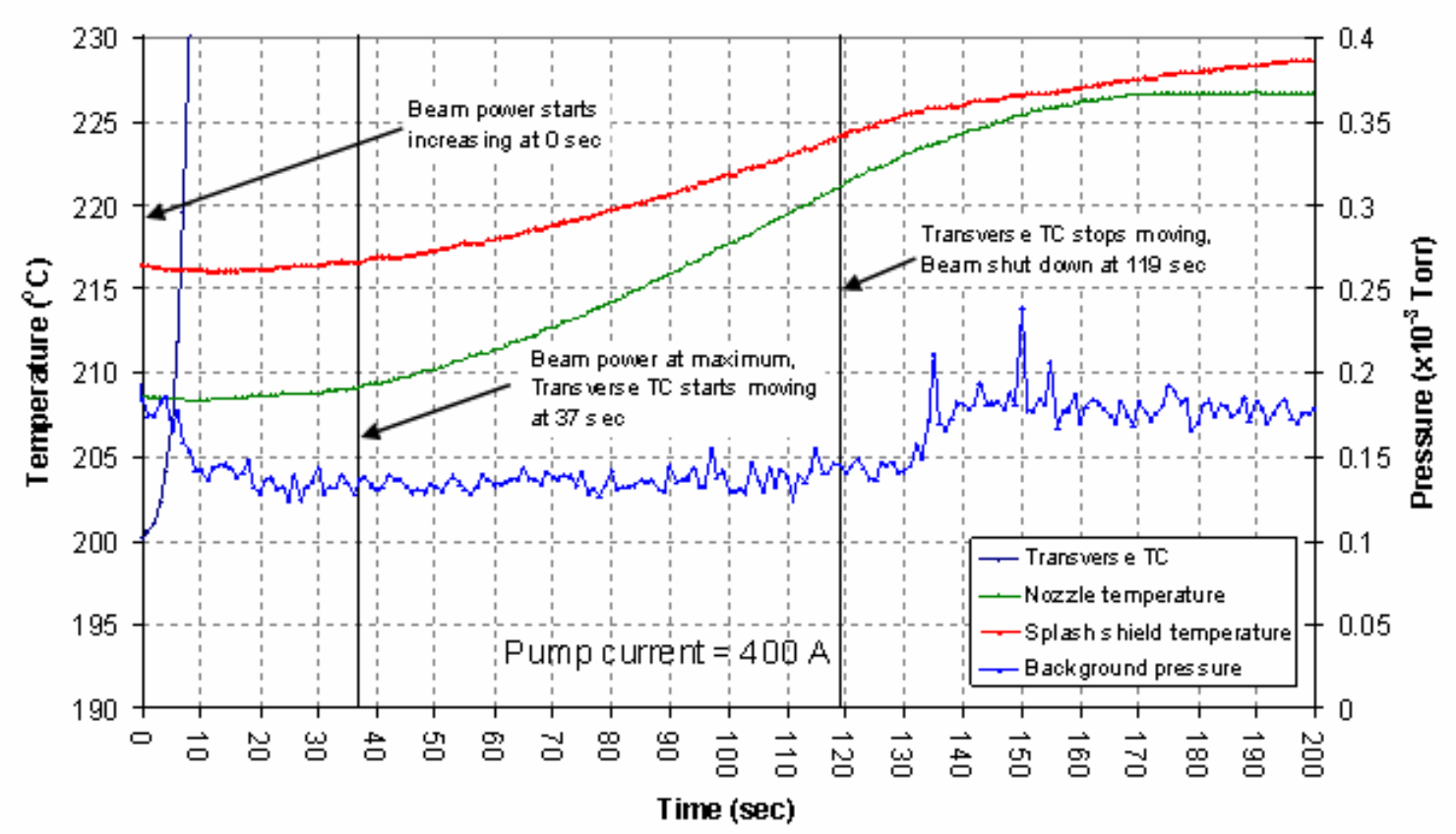

Figure 17. Measured Nozzle and Splash Shield Temperatures.

\section{Summary and Conclusions}

Experiments were performed to demonstrate the stable formation of a liquid lithium jet that simulates the windowless liquid lithium target under a thermal load similar to that of RIA using a $1 \mathrm{MeV}$ electron beam. Stable jet formation under beam powers up to $20 \mathrm{~kW}$ were confirmed at a jet velocity as low as $1.8 \mathrm{~m} / \mathrm{s}$. A 55 second beam irradiation at $20 \mathrm{~kW}$ resulted in a temperature rise of only $\sim 30{ }^{\circ} \mathrm{C}$ in bulk lithium temperature and a background pressure rise of only $\sim 0.3 \mathrm{mTorr}$. Attempts to measure the spatial temperature distribution across the jet were also made using a traversing TC and an IR camera; however, emitted X-rays internally heated up the tip of the TC, resulting in inaccurate temperature measurements. The surface of the liquid lithium appeared to reflect the surrounding emission and the temperature readings from the IR camera were unreasonably low. 


\section{References}

[1] Nolen, J. A., Reed, C. B., Hassanein, A., and Gomes, I. C., "Liquid-lithium cooling for 100-kW ISOL and fragmentation targets,” Nucl. Phys. A 701, pp312c-322c, 2002.

[2] Nolen, J. A., “Overview of the U.S. Rare Isotope Accelerator Proposal,” Nucl. Phys., A734, pp661-668, 2004.

[3] Nolen, J. A., Specht, J. B., Kanter, E., Sienicki, J. J., Tzanos, C. P., Reed, C. B., and Novick, V. J., "High-power liquid-lithium targets and strippers," Research and Development for the Rare Isotope Accelerator, Solicitation Number: DE-FG01-02ER0227), 2002.

[4] Nolen, J. A., Reed, C. B., Hassanein, A., Novick, V. J., Plotkin, P., and Specht, J. R., "Development of Windowless Liquid Lithium Targets for Fragmentation and Fission of 400-kW Uranium Beams,” Nucl. Instr. Meth. B, pp293-297, 2003.

[5] Reed, C. B., "Convective Heat Transfer in Liquid Metals," in Handbook of SinglePhase Convective Heat Transfer, John Wiley \& Sons, Inc., edited by S. Kakac, R. K. Shah, and W. Aung, 1986.

[6] Hoffman, E. E., "Corrosion of Materials by Lithium at Elevated Temperatures," USAEC Report, ORNL-2674, 1959.

[7] Chopra, O. K. and Smith, D. L., "Influence of Temperature and Lithium Purity on Corrosion of Ferrous Alloys in a Flowing Lithium Environment,” J. Nucl. Matter., v.141143, pp584-591, 1986.

[8] Chopra, O. K. and Smith, D. L., "Corrosion Behavior of Vanadium Alloys in Flowing Lithium,” J. Nucl. Matter., v.155-157, pp683-689, 1988.

[9] Nolen, J. A., Reed, C. B., Hassanein, A., Novick, V. J., Plotkin, P., Specht, J. R., and Morrissey, D. J., Ottarson, J. H., and Sherrill, B. M., "An Adjustable Thickness Li/Be Target for Fragmentation of 4 kW Heavy Ion Beams,” Nucl. Instr. Meth. B, pp298-302, 2003.

[10] Achener, P. Y., Alkali Metals Evaluation Program Quarterly Progress Report, 1 October through 31 December 1966, Report No. AGN-8215, Nuclear Products and Services Group, Aerojet-General Corporation, San Ramon, CA.

[11] Laurie Waters, editor, “MCNPX User’s Manual - Version 2.3.0”, April 2002, LAUR-02-2607.

[12] Origin - Microcal Software Inc. One Roundhouse Plaza, Northhampton, MA 01060 USA. 
Table 1. Energy deposition at selected positions inside the lithium jet for 1-MeV electrons. The position $(0,0)$ is at the center of the beam where the beam strikes the lithium jet.

\begin{tabular}{|c|c|c|c|c|c|c|c|}
\hline \multirow{2}{*}{$\begin{array}{l}\text { Position } \\
\text { in Axial } \\
\text { Direction }\end{array}$} & \multicolumn{7}{|c|}{ Positions Along the Radial Direction } \\
\hline & $\begin{array}{c}\text { From } 0 \text { to } \\
0.1 \mathrm{~mm}\end{array}$ & $\begin{array}{l}\text { From } 0.1 \\
\text { to } 0.2 \mathrm{~mm}\end{array}$ & $\begin{array}{l}\text { From } 0.2 \\
\text { to } 0.3 \mathrm{~mm}\end{array}$ & $\begin{array}{l}\text { From } 0.3 \\
\text { to } 0.4 \mathrm{~mm}\end{array}$ & $\begin{array}{l}\text { From } 0.4 \\
\text { to } 0.5 \mathrm{~mm}\end{array}$ & $\begin{array}{l}\text { From } 0.5 \\
\text { to } 0.6 \mathrm{~mm}\end{array}$ & $\begin{array}{l}\text { From } 0.6 \\
\text { to } 0.7 \mathrm{~mm}\end{array}$ \\
\hline 0.015 & 97.961 & 98.311 & 97.612 & 97.545 & 95.846 & 1.7295 & 0.43022 \\
\hline 0.045 & 100.44 & 101.46 & 100.98 & 100.65 & 92.203 & 7.5968 & 1.057 \\
\hline 0.075 & 101.99 & 103.07 & 102.54 & 100.17 & 80.593 & 18.597 & 2.571 \\
\hline 0.105 & 103.45 & 103.47 & 101.55 & 94.178 & 69.333 & 27.973 & 7.5924 \\
\hline 0.135 & 101.49 & 100.22 & 95.561 & 83.37 & 60.938 & 32.968 & 14.426 \\
\hline 0.165 & 92.714 & 91.38 & 84.029 & 71.886 & 54.148 & 34.616 & 19.743 \\
\hline 0.195 & 79.524 & 77.936 & 71.385 & 61.125 & 48.154 & 34.431 & 22.898 \\
\hline 0.225 & 64.707 & 63.355 & 58.443 & 51.072 & 41.876 & 32.387 & 23.787 \\
\hline 0.255 & 50.652 & 50.299 & 47.052 & 42.124 & 35.953 & 29.183 & 23.096 \\
\hline 0.285 & 40.181 & 39.65 & 37.502 & 34.417 & 30.285 & 25.652 & 21.373 \\
\hline 0.315 & 31.299 & 31.023 & 29.784 & 27.915 & 25.102 & 22.128 & 18.999 \\
\hline 0.345 & 24.493 & 24.708 & 24.005 & 22.615 & 20.956 & 18.841 & 16.662 \\
\hline 0.375 & 19.503 & 19.814 & 19.123 & 18.434 & 17.275 & 15.892 & 14.481 \\
\hline 0.405 & 15.632 & 15.997 & 15.852 & 15.094 & 14.348 & 13.492 & 12.393 \\
\hline 0.435 & 12.843 & 13.051 & 12.843 & 12.486 & 12.027 & 11.423 & 10.659 \\
\hline 0.465 & 10.698 & 10.764 & 10.696 & 10.417 & 10.029 & 9.6862 & 9.1664 \\
\hline 0.495 & 8.7782 & 9.0165 & 8.9322 & 8.7616 & 8.4724 & 8.1767 & 7.8721 \\
\hline 0.525 & 7.4091 & 7.5302 & 7.5841 & 7.4816 & 7.2877 & 7.0683 & 6.8483 \\
\hline 0.555 & 6.4235 & 6.5166 & 6.4538 & 6.4015 & 6.281 & 6.0977 & 5.975 \\
\hline 0.585 & 5.5216 & 5.5265 & 5.6116 & 5.6042 & 5.4671 & 5.3638 & 5.2325 \\
\hline 0.615 & 4.7945 & 4.9268 & 4.9019 & 4.8971 & 4.8568 & 4.7803 & 4.664 \\
\hline 0.645 & 4.2281 & 4.3607 & 4.4242 & 4.4109 & 4.3473 & 4.2985 & 4.2003 \\
\hline 0.675 & 3.9687 & 3.9889 & 4.0186 & 3.9452 & 3.9326 & 3.8711 & 3.8074 \\
\hline 0.705 & 3.6795 & 3.704 & 3.6287 & 3.6162 & 3.5895 & 3.5204 & 3.5196 \\
\hline 0.735 & 3.2952 & 3.3384 & 3.2904 & 3.333 & 3.2887 & 3.2909 & 3.2319 \\
\hline 0.765 & 3.0672 & 3.0291 & 3.0553 & 3.0575 & 3.0351 & 3.053 & 3.0092 \\
\hline 0.795 & 2.7877 & 2.892 & 2.7938 & 2.8113 & 2.7755 & 2.7928 & 2.7609 \\
\hline 0.825 & 2.4763 & 2.5339 & 2.5409 & 2.4652 & 2.4892 & 2.449 & 2.4767 \\
\hline 0.855 & 2.0815 & 2.2143 & 2.1935 & 2.1134 & 2.096 & 2.102 & 2.0942 \\
\hline 0.885 & 1.6866 & 1.6761 & 1.7161 & 1.6866 & 1.6688 & 1.6688 & 1.6158 \\
\hline 0.915 & 1.2455 & 1.2345 & 1.2412 & 1.2473 & 1.2311 & 1.2384 & 1.1857 \\
\hline 0.945 & 0.6926 & 0.72976 & 0.7469 & 0.75336 & 0.76227 & 0.75999 & 0.77155 \\
\hline 0.975 & 0.38659 & 0.39263 & 0.40228 & 0.38206 & 0.38513 & 0.39721 & 0.38643 \\
\hline
\end{tabular}


Table 2. Energy deposition at selected positions inside the lithium jet for $3-\mathrm{MeV}$ electrons. The position $(0,0)$ is at the center of the beam where the beam strikes the lithium jet.

\begin{tabular}{|c|c|c|c|c|c|c|c|}
\hline \multirow{2}{*}{$\begin{array}{l}\text { Position in } \\
\text { Axial } \\
\text { Direction }\end{array}$} & \multicolumn{7}{|c|}{ Positions Along the Radial Direction } \\
\hline & $\begin{array}{c}\text { From } 0 \text { to } \\
0.1 \mathrm{~mm}\end{array}$ & $\begin{array}{l}\text { From } 0.1 \\
\text { to } 0.2 \mathrm{~mm}\end{array}$ & $\begin{array}{l}\text { From } 0.2 \\
\text { to } 0.3 \mathrm{~mm}\end{array}$ & $\begin{array}{l}\text { From } 0.3 \\
\text { to } 0.4 \mathrm{~mm}\end{array}$ & $\begin{array}{l}\text { From } 0.4 \\
\text { to } 0.5 \mathrm{~mm}\end{array}$ & $\begin{array}{l}\text { From } 0.5 \\
\text { to } 0.6 \mathrm{~mm}\end{array}$ & $\begin{array}{l}\text { From } 0.6 \\
\text { to } 0.7 \mathrm{~mm}\end{array}$ \\
\hline 0.015 & 92.713 & 93.031 & 92.235 & 92.008 & 90.195 & 1.804 & 0.51737 \\
\hline 0.045 & 93.243 & 95.042 & 94.216 & 93.937 & 89.408 & 4.4598 & 1.0453 \\
\hline 0.075 & 94.486 & 95.014 & 94.883 & 94.377 & 84.862 & 8.9783 & 1.3144 \\
\hline 0.105 & 94.779 & 95.218 & 94.616 & 94.407 & 78.273 & 14.586 & 1.724 \\
\hline 0.135 & 95.361 & 95.605 & 94.592 & 92.248 & 71.183 & 20.32 & 2.8974 \\
\hline 0.165 & 95.084 & 94.752 & 94.317 & 88.568 & 64.989 & 24.843 & 5.3354 \\
\hline 0.195 & 94.9 & 95.323 & 92.329 & 83.242 & 60.16 & 28.051 & 8.7873 \\
\hline 0.225 & 94.561 & 93.39 & 88.096 & 77.135 & 55.666 & 30.007 & 12.278 \\
\hline 0.255 & 90.942 & 89.414 & 83.222 & 70.88 & 51.873 & 31.143 & 15.26 \\
\hline 0.285 & 86.834 & 84.563 & 77.571 & 65.432 & 48.972 & 31.529 & 17.812 \\
\hline 0.315 & 82.052 & 78.398 & 71.056 & 59.798 & 45.52 & 31.662 & 19.667 \\
\hline 0.345 & 74.243 & 71.362 & 63.844 & 54.173 & 42.836 & 30.957 & 20.609 \\
\hline 0.375 & 66.615 & 62.931 & 57.486 & 49.292 & 39.835 & 29.97 & 21.244 \\
\hline 0.405 & 57.927 & 55.85 & 50.789 & 44.183 & 36.892 & 28.688 & 21.356 \\
\hline 0.435 & 51.092 & 49.049 & 44.98 & 39.83 & 33.816 & 27.43 & 21.268 \\
\hline 0.465 & 44.141 & 43.044 & 39.961 & 35.69 & 30.903 & 25.63 & 20.556 \\
\hline 0.495 & 38.049 & 37.554 & 34.838 & 31.657 & 28.117 & 23.769 & 19.732 \\
\hline 0.525 & 33.426 & 32.434 & 30.762 & 28.258 & 25.191 & 22.179 & 18.554 \\
\hline 0.555 & 29.669 & 28.237 & 26.879 & 25.069 & 22.781 & 20.048 & 17.444 \\
\hline 0.585 & 25.325 & 25.054 & 23.794 & 22.101 & 20.39 & 18.252 & 16.26 \\
\hline 0.615 & 22.169 & 21.671 & 21.066 & 19.855 & 18.296 & 16.771 & 15.019 \\
\hline 0.645 & 19.765 & 19.187 & 18.531 & 17.64 & 16.237 & 15.257 & 13.705 \\
\hline 0.675 & 16.589 & 16.939 & 16.285 & 15.756 & 14.879 & 13.726 & 12.537 \\
\hline 0.705 & 15.036 & 15.108 & 14.5 & 14.036 & 13.251 & 12.449 & 11.475 \\
\hline 0.735 & 13.336 & 13.233 & 12.787 & 12.543 & 11.899 & 11.213 & 10.547 \\
\hline 0.765 & 11.943 & 11.888 & 11.613 & 11.275 & 10.652 & 10.212 & 9.6161 \\
\hline 0.795 & 10.425 & 10.476 & 10.339 & 10.1 & 9.7014 & 9.221 & 8.7645 \\
\hline 0.825 & 9.5097 & 9.6165 & 9.4043 & 9.1633 & 8.7971 & 8.375 & 7.9984 \\
\hline 0.855 & 8.307 & 8.5578 & 8.3584 & 8.2993 & 7.9726 & 7.6574 & 7.2874 \\
\hline 0.885 & 7.546 & 7.6504 & 7.4825 & 7.3446 & 7.2676 & 7.0346 & 6.6644 \\
\hline 0.915 & 6.6661 & 6.8989 & 6.9218 & 6.6477 & 6.5788 & 6.3929 & 6.155 \\
\hline 0.945 & 6.3816 & 6.2866 & 6.2048 & 6.1061 & 5.9582 & 5.8732 & 5.6979 \\
\hline 0.975 & 5.3498 & 5.7603 & 5.7266 & 5.5833 & 5.529 & 5.3986 & 5.1156 \\
\hline
\end{tabular}


Table 3. Energy deposition at selected positions inside the lithium jet for $3-\mathrm{MeV}$ electrons. The position $(0,0)$ is at the center of the beam where the beam strikes the lithium jet.

\begin{tabular}{|c|c|c|c|c|c|c|c|}
\hline \multirow{2}{*}{$\begin{array}{l}\text { Position in } \\
\text { Axial } \\
\text { Direction }\end{array}$} & \multicolumn{7}{|c|}{ Positions Along the Radial Direction } \\
\hline & $\begin{array}{c}\text { From } 0 \text { to } \\
0.1 \mathrm{~mm}\end{array}$ & $\begin{array}{l}\text { From } 0.1 \\
\text { to } 0.2 \mathrm{~mm}\end{array}$ & $\begin{array}{l}\text { From } 0.2 \\
\text { to } 0.3 \mathrm{~mm}\end{array}$ & $\begin{array}{l}\text { From } 0.3 \\
\text { to } 0.4 \mathrm{~mm}\end{array}$ & $\begin{array}{l}\text { From } 0.4 \\
\text { to } 0.5 \mathrm{~mm}\end{array}$ & $\begin{array}{l}\text { From } 0.5 \\
\text { to } 0.6 \mathrm{~mm}\end{array}$ & $\begin{array}{l}\text { From } 0.6 \\
\text { to } 0.7 \mathrm{~mm}\end{array}$ \\
\hline 0.015 & 93.182 & 93.264 & 92.364 & 92.007 & 90.391 & 1.8236 & 0.53482 \\
\hline 0.045 & 93.197 & 95.378 & 94.106 & 93.662 & 89.984 & 3.7387 & 1.0824 \\
\hline 0.075 & 94.052 & 94.757 & 94.789 & 94.145 & 87.681 & 6.6474 & 1.2945 \\
\hline 0.105 & 95.009 & 95.843 & 94.516 & 94.087 & 83.865 & 10.192 & 1.4562 \\
\hline 0.135 & 95.989 & 95.778 & 94.498 & 93.735 & 78.477 & 14.417 & 1.7124 \\
\hline 0.165 & 94.553 & 95.455 & 94.834 & 93.421 & 72.966 & 18.709 & 2.3483 \\
\hline 0.195 & 95.346 & 95.075 & 94.992 & 91.332 & 68.624 & 22.375 & 3.6357 \\
\hline 0.225 & 95.671 & 95.016 & 93.408 & 87.807 & 64.142 & 25.393 & 5.6787 \\
\hline 0.255 & 95.51 & 94.383 & 91.985 & 83.841 & 60.143 & 27.621 & 8.1341 \\
\hline 0.285 & 94.628 & 93.495 & 90.044 & 79.242 & 56.54 & 29.308 & 10.753 \\
\hline 0.315 & 92.911 & 91.484 & 86.333 & 74.583 & 53.733 & 30.445 & 13.335 \\
\hline 0.345 & 91.869 & 89.182 & 83.002 & 69.979 & 51.347 & 31.062 & 15.569 \\
\hline 0.375 & 88.397 & 85.41 & 77.79 & 65.914 & 49.063 & 31.4 & 17.281 \\
\hline 0.405 & 85.44 & 81.335 & 73.167 & 61.515 & 46.64 & 31.392 & 18.755 \\
\hline 0.435 & 80.06 & 76.635 & 68.33 & 57.702 & 44.263 & 31.324 & 19.774 \\
\hline 0.465 & 75.24 & 70.317 & 63.941 & 53.949 & 41.971 & 30.696 & 20.646 \\
\hline 0.495 & 67.799 & 65.216 & 58.987 & 50.273 & 40.215 & 30.094 & 21.065 \\
\hline 0.525 & 62.955 & 60.359 & 53.798 & 46.56 & 38.056 & 29.45 & 21.367 \\
\hline 0.555 & 57.133 & 55.144 & 50.011 & 43.185 & 35.684 & 28.245 & 21.369 \\
\hline 0.585 & 51.597 & 49.052 & 45.269 & 39.939 & 33.584 & 26.965 & 20.96 \\
\hline 0.615 & 46.37 & 44.866 & 41.327 & 36.509 & 31.443 & 26.021 & 20.6 \\
\hline 0.645 & 41.94 & 40.383 & 37.585 & 33.915 & 29.405 & 24.854 & 20.029 \\
\hline 0.675 & 37.924 & 37.112 & 34.001 & 31.154 & 27.265 & 23.376 & 19.392 \\
\hline 0.705 & 33.96 & 33.386 & 30.74 & 28.447 & 25.556 & 21.925 & 18.493 \\
\hline 0.735 & 31.285 & 29.63 & 27.854 & 26.201 & 23.326 & 20.759 & 17.701 \\
\hline 0.765 & 27.745 & 26.888 & 25.714 & 23.74 & 21.689 & 19.44 & 16.79 \\
\hline 0.795 & 24.744 & 24.146 & 23.305 & 21.685 & 20.086 & 18.204 & 15.952 \\
\hline 0.825 & 22.619 & 22.211 & 21.093 & 20.136 & 18.312 & 16.859 & 15.124 \\
\hline 0.855 & 19.991 & 20.24 & 19.324 & 18.416 & 17.132 & 15.77 & 14.198 \\
\hline 0.885 & 18.283 & 18.443 & 17.716 & 16.831 & 15.802 & 14.475 & 13.358 \\
\hline 0.915 & 17.096 & 16.657 & 16.179 & 15.613 & 14.626 & 13.585 & 12.491 \\
\hline 0.945 & 15.846 & 15.165 & 14.761 & 14.296 & 13.584 & 12.527 & 11.718 \\
\hline 0.975 & 14.004 & 14.438 & 13.45 & 13.112 & 12.521 & 11.66 & 10.906 \\
\hline
\end{tabular}

